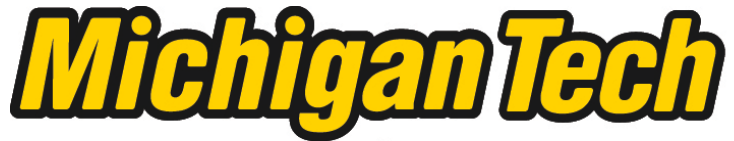 \\ Michigan Technological University Create the Future Digital Commons @ Michigan Tech
}

Dissertations, Master's Theses and Master's Reports - Open

Dissertations, Master's Theses and Master's

Reports

2013

Plant-mediated effects on microbial diversity in mesocosms of an oligotrophic bog

Karl J. Romanowicz IV

Michigan Technological University

Follow this and additional works at: https://digitalcommons.mtu.edu/etds

Part of the Ecology and Evolutionary Biology Commons, and the Microbiology Commons Copyright 2013 Karl J. Romanowicz IV

\section{Recommended Citation}

Romanowicz, Karl J. IV, "Plant-mediated effects on microbial diversity in mesocosms of an oligotrophic bog", Master's Thesis, Michigan Technological University, 2013.

https://doi.org/10.37099/mtu.dc.etds/626

Follow this and additional works at: https://digitalcommons.mtu.edu/etds

Part of the Ecology and Evolutionary Biology Commons, and the Microbiology Commons 


\title{
PLANT-MEDIATED EFFECTS ON MICROBIAL DIVERSITY IN MESOCOSMS OF AN OLIGOTROPHIC BOG
}

\author{
By \\ Karl J. Romanowicz IV
}

\begin{abstract}
A THESIS
Submitted in partial fulfillment of the requirements for the degree of MASTER OF SCIENCE

In Applied Ecology
\end{abstract}

MICHIGAN TECHNOLOGICAL UNIVERSITY

2013

Copyright ( Karl J. Romanowicz 2013 
This thesis has been approved in partial fulfillment of the requirements for the Degree of MASTER OF SCIENCE in Applied Ecology.

School of Forest Resources and Environmental Science

$\begin{array}{cc}\text { Thesis Advisor: } & \text { Erik A. Lilleskov } \\ \text { Committee Member: } & \text { Rodney A. Chimner } \\ \text { Committee Member: } & \text { Sarah A. Green } \\ \text { Committee Member: } & \text { Jay T. Lennon }\end{array}$

School Dean: $\quad$ Terry L. Sharik 


\section{TABLE OF CONTENTS}

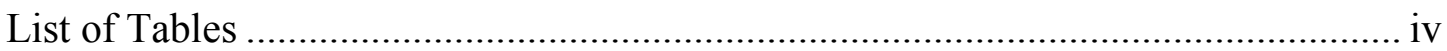

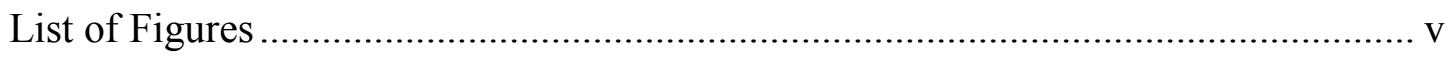

List of Supplemental Tables .............................................................................. vi

List of Supplemental Figures ........................................................................... vi

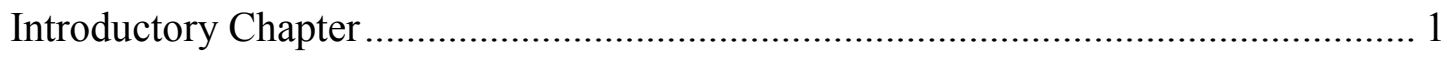

Chapter 1. Plant-Mediated Effects on Microbial Diversity in Mesocosms of an

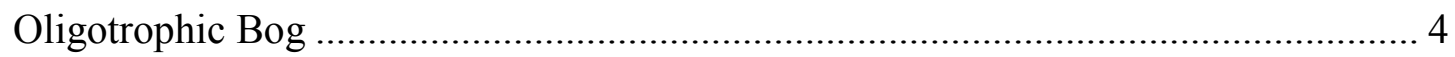

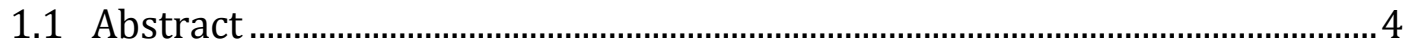

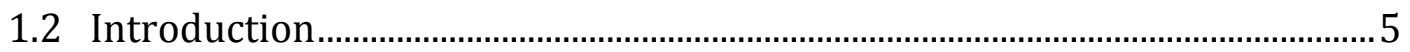

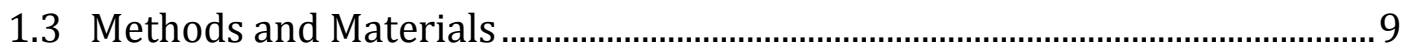

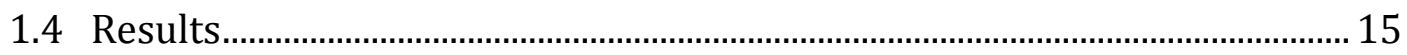

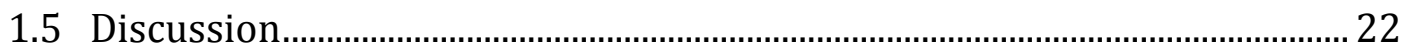

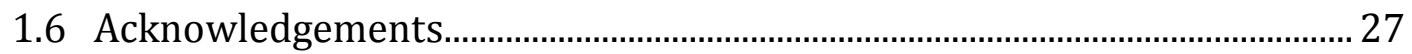

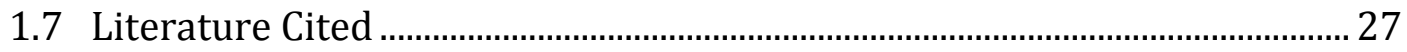

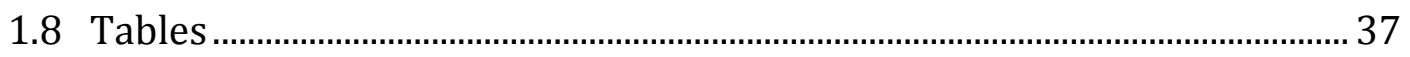

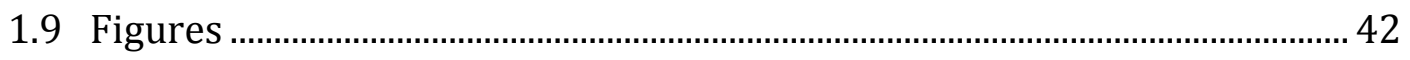

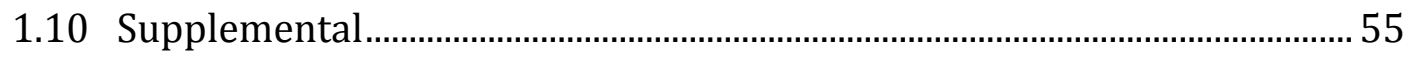




\section{LIST OF TABLES}

Table 1 Oxidative and hydrolytic extracellular enzymes assayed in bulk peat at the 10-20 cm depth with corresponding enzyme commission number (EC), role in nutrient cycling, and substrate.

Table 2 Bacterial and archaeal diversity indicated by Chao1 richness and equitability evenness in plant functional group treatments............................................................ 38

Table 3 Mean ( \pm SE) percent relative abundance of bacterial phyla and archaeal orders between plant functional groups within sampling depths.

Table 4 Peat soil biogeochemistry, relative percentage of vegetation, and extracellular enzyme activities by plant functional group treatments within depths. . 40

Table 5 Statistical results for envfit function utilizing environmental data for bacteria and archaea at both $10-20 \mathrm{~cm}$ and $30-40 \mathrm{~cm}$ depths. 


\section{LIST OF FIGURES}

Figure 1 Rank abundance curves for relative abundance of A) bacterial and B) archaeal OTUs obtained from Illumina sequencing

Figure 2 Water table depth in mesocosm bins for high water table treatment (HWT) and low water table treatment (LWT) during the two-week peat coring period.

Figure 3 Bacteria phylum-level community composition between sampling depth.. 44

Figure 4 Bacteria phylum-level community composition between plant functional group treatments within sampling depths

Figure 5 Archaea order-level community composition between sampling depth. .... 46

Figure 6 Archaea order-level community composition between plant functional group treatments within sampling depths.

Figure 7 Heatmap visualization for top 100 most abundant bacterial OTUs indicating relative abundance by depth. 48

Figure 8 Heatmap visualization for all archaeal OTUs indicating relative abundance by depth......

Figure 9 Principal coordinates analysis of A) bacteria and B) archaea. 50

Figure 10 PCoA of top 100 OTUs with envfit environmental vectors for A) bacteria at $10-20 \mathrm{~cm}$ depth and B) bacteria at $30-40 \mathrm{~cm}$ depth.

Figure 11 PCoA of all OTUs with envfit environmental vectors for A) archaea at 10$20 \mathrm{~cm}$ depth and B) archaea at 30-40 $\mathrm{cm}$ depth

Figure 12 Mean relative abundance of all methanotrophic bacteria summed between sampling depths

Figure 13 Mean relative abundance of all methanogenic archaea summed between sampling depths 


\section{LiST OF SUPPLEMENTAL TABLES}

Table S1 Depth effects on top 50 most abundant bacterial OTUs as calculated through the OTU Category Significance ANOVA in QIIME.

Table S2 Depth effects on archaeal OTUs as calculated through the OTU Category Significance ANOVA in QIIME and list of all archaeal OTUs with consensus lineage from the oligotrophic bog mesocosm study. 56

\section{LIST OF SUPPLEMENTAL FIGURES}

Figure S1 Electrophoresis DNA quantity visualization on 2:1\% agarose gel for DNA extractions at the $10-20 \mathrm{~cm}$ depth.

Figure S2 Electrophoresis DNA quantity visualization on 2:1\% agarose gel for DNA extractions at the $30-40 \mathrm{~cm}$ depth.

Figure S3 Relative abundance of all known methanotrophic bacteria within plant functional group treatments between sampling depths as found in this study.

Figure S4 Mean relative abundance of all known methanogenic archaea plus unclassified Euryarchaeota within plant functional group treatments between sampling depths as found in this study. 


\section{INTRODUCTORY CHAPTER}

Northern peatlands form in moderately cool yet wet climatic zones where photosynthetic capacity of vegetation exceeds decomposition. Accumulating slowly throughout the Holocene, these peat deposits now cover approximately $3 \%$ of terrestrial land area and store up to one-third of global terrestrial carbon stocks. This vast carbon store has the potential to contribute substantial feedbacks to global climate change, as the balance between carbon inputs from vegetation and carbon loss from decomposition is relatively sensitive to changing climate. Changes in plant communities may lead to feedbacks altering the carbon balance of peatlands. No study to date has tested the direct effects of dominant plant functional group manipulations within an oligotrophic bog on rhizosphere microbial communities and their associated functions.

The two major vascular plant functional groups in northern peatlands are sedges and shrubs of the family Ericaceae. Specific traits of these two functional groups are hypothesized to drive opposing effects on peatland carbon balance. Sedge species contain aerenchyma that function as a ventilation system by transporting oxygen to the root tips in saturated, anaerobic soil while simultaneously transporting carbon dioxide $\left(\mathrm{CO}_{2}\right)$ and methane $\left(\mathrm{CH}_{4}\right)$ from the soil to the atmosphere. As a result of aerenchyma, sedges serve as direct channels that bypass oxidizing environments and influence rhizospheric processes regardless of water table levels. Sedges are hypothesized to create extensive carbon oxidation and mineralization hotspots throughout the peat profile and may lead to enhanced aerobic microbial activity near root surfaces promoting increased peat subsidence and negative carbon balance. In contrast, ericaceous shrubs are hypothesized to drive decreased carbon mineralization by mediating changes in rhizosphere microbial communities and enzyme activity. Ericaceous shrubs lack aerenchyma, have poor litter quality, and utilize enzymatically active ericoid mycorrhizal fungi that may suppress free-living saprotrophs through 
direct interception of necessary macronutrients such as nitrogen and phosphorous. This potential combination of decreased carbon mineralization and increased net primary production (NPP) could drive continued positive carbon balance.

This thesis documents the response of rhizosphere microbial communities to changes in plant functional groups in a mesocosm-based experimental design. Research was conducted at the Houghton Mesocosm Facility at the USDA Forest Service Northern Research Station Forestry Sciences Laboratory in Houghton, Mich., USA. Peat monoliths were harvested and housed in mesocosm chambers in May 2010 and underwent plant functional groups manipulations in July 2011. Mesocosms were manipulated into three vegetation treatments: unmanipulated (+sedge, +Ericaceae), sedge (+sedge, -Ericaceae), and Ericaceae (-sedge, +Ericaceae). The Houghton Mesocosm Facility provided fine-scale control of plant community composition allowing us to investigate how carbon-based rhizospheric processes in peatland ecosystems would respond under predicted future climate change scenarios.

Our research explored the impacts of plant functional groups on rhizosphere microbial community composition at two depths from cores collected during September 2011. These samples represent microbial community composition approximately two months following plant functional group manipulations under anaerobic soil conditions created by high water table levels. Microbial DNA was extracted from both $10-20 \mathrm{~cm}$ and $30-40 \mathrm{~cm}$ depths (both depths were below water table levels at time of sampling) from each mesocosm core and sequenced for bacterial and archaeal community composition through 16S rRNA targeted gene sequencing on an Illumina MiSeq platform.

Results indicated significant differences in bacterial and archaeal community composition between sampling depths. Heterogeneity within bacterial community 
composition decreased with increasing depth in the peat soil, and was paralleled by an increase in the relative abundance of anaerobic taxa. Plant functional groups had no significant influence at the 30-40 cm depth, however, within the more shallow 10-20 $\mathrm{cm}$ depth, plant functional groups significantly influenced certain bacterial and archaeal communities. These results implied increased microbial heterogeneity within the 10-20 cm depth under the Ericaceae treatment, incorporating a more even distribution of Acidobacteria, Bacteroidetes and Gammaproteobacteria. Sedge treatments experienced an increase in the relative dominance of Acidobacteria, while also encouraging significant increases in Alphaproteobacteria, and Verrucomicrobia, which are known to contain methane-oxidizing taxa and warranted a more thorough examination. Sampling depth significantly influenced the relative abundance of both methane-oxidizing bacteria and methanogenic archaea, but there were no significant effects of plant functional groups. These results suggest that the bacteria and archaea involved in methane oxidation or production, respectively, are not directly influenced by plant functional groups following such a short timeframe from manipulations.

Although these are early results in a long-term mesocosm study, they provide essential information regarding initial shifts in the relative abundance of microbial community composition under specific plant functional group manipulations. Results from our mesocosm-based study have begun to test whether plant functional groups have the potential to significantly alter the mechanisms controlling carbon-based rhizospheric processes by fundamentally changing microbial community composition. 


\section{Chapter 1. Plant-Mediated Effects on Microbial Diversity in Mesocosms OF AN OLIGOTROPHIC BOG}

\subsection{Abstract}

Globally, peatlands occupy a small portion of terrestrial land area but contain up to one-third of all soil organic carbon. This carbon pool is vulnerable to increased decomposition under projected climate change scenarios but little is known about how plant functional groups will influence microbial communities responsible for regulating carbon cycling processes. Here we examined initial shifts in microbial community structure within two sampling depths under plant functional group manipulations in mesocosms of an oligotrophic bog. Microbial community composition for bacteria and archaea was characterized using targeted 16S rRNA Illumina gene sequencing. We found statistically distinct spatial patterns between the more shallow 10-20 cm sampling depth and the deeper 30-40 cm depth. Significant effects by plant functional groups were found only within the $10-20 \mathrm{~cm}$ depth, indicating plant-mediated microbial community shifts respond more quickly near the peat surface. Specifically, the relative abundance of Acidobacteria decreased under ericaceous shrub treatments in the 10-20 cm depth and was replaced by increased abundance of Gammaproteobacteria and Bacteroidetes. In contrast, the sedge rhizosphere continued to be dominated by Acidobacteria but also promoted an increase in the relative recovery of Alphaproteobacteria and Verrucomicrobia. These initial results suggest microbial communities under ericaceous shrubs may be limited by anaerobic soil conditions accompanying high water table conditions, while sedge aerenchyma may be promoting aerobic taxa in the upper peat rhizosphere regardless of ambient soil oxygen limitations. 


\subsection{Introduction}

Northern peatlands store approximately a third of all terrestrial soil carbon in the form of partially decayed organic peat (Gorham, 1991; Clymo et al., 1998) while also emitting 9-18\% of all global atmospheric methane (Laanbroek, 2009). Carbon storage is a result of high water table levels and subsequent oxygen limitation in peat soils that favors primary production over decomposition (Clymo, 1984). The unique hydrology of peatlands promotes anaerobic soil conditions that stimulate methanogenic microorganisms to produce methane $\left(\mathrm{CH}_{4}\right)$ as the terminal step in anoxic microbial degradation of organic matter (Sundh et al., 1994). Historically, peatlands have served as net carbon sinks but could transition to carbon sources if water tables become lowered as a result of climate change or anthropogenic drainage (Trettin et al., 2006; Dinsmore et al., 2010). Shifts in the environmental and physicochemical constraints on microbial decomposition could alter carbon cycling and methane production/consumption processes (Andersen et al., 2012). This could lead to increased peat oxidation to carbon dioxide $\left(\mathrm{CO}_{2}\right)$, while limiting methane production as anaerobic soil conditions decline. However, plant functional groups have the ability to regulate soil microbial processes by influencing litter quality (Joanisse et al., 2007), oxygen availability (Strack et al., 2006), root exudation (Inderjit \& Mallik, 2002), and nutrient competition (Bonfante \& Genre, 2010; Artz et al., 2007). To our knowledge, no study has been conducted to specifically test the direct consequences of spatial and temporal changes to peatland plant functional groups on microbial community structure and function.

Bogs are oligotrophic peatlands deriving limited nutrient inputs mainly from precipitation (Crum, 1991). Northern regions have experienced increasing variability in precipitation patterns in recent decades (Tsonis et al., 1996; Groisman et al., 2005) causing declines in peatland water tables and increased frequency and intensity of mid-summer water table drawdown (Roulet et al., 1992; Hilbert et al., 2000). 
Sustained changes in peatland water table levels have been shown to directly influence the establishment of plant functional groups (Breeuwer et al., 2009; Weltzin et al., 2000). Dominant groups of bog plant communities include Sphagnum mosses, sedges, and ericaceous shrubs (Crum, 1991). Sphagnum lack root systems and form dense lawns on the surface of peatlands (Strack et al., 2006) where they attract water to the surface through capillary forces (Farrick, 2009). Sedges are perennial graminoids that use aerenchyma to promote diffusion of oxygen to deep roots in anoxic peat and subsequently create extensive carbon oxidation and mineralization hotspots (Holzapfel-Pschorn et al., 1986). In contrast, ericaceous shrubs are shallowly rooted and form a symbiotic relationship with enzymatically active ericoid mycorrhizal fungi (Cairney \& Burke, 1998) possibly suppressing free-living heterotroph activity and promoting decreased carbon mineralization. In essence, root traits are predicted to be dominant regulators of microbially mediated soil processes as they alter carbon and nutrient resources and influence rhizosphere conditions suitable for specific functional groups of microorganisms (Andersen et al., 2012; Strakova et al., 2011).

Acidic, nutrient-poor conditions in bogs are a major constraint on bacterial community composition (Dedysh et al., 1998), along with energetic constraints such as decreased availability of oxygen and high quality electron acceptors with increasing depth in the peat column (Artz, 2009). However, plant functional groups have the ability to modify environmental conditions and subsequently alter microbial composition such that sedge dominated peatlands can harbor significantly different communities from ericaceous shrub peatlands (Fisk et al., 2003; Borga et al., 1994). Archaeal community structure also seems to be substrate and plant specific as observed differences were found in community composition among plant species within the rhizosphere (Cadillo-Quiroz et al., 2009). Ericoid mycorrhizal fungi are a prime example of a plant-dependent microbe and are hypothesized to dominate upper surface layers in ericaceous shrub peatlands, promoting enzyme activity primarily 
focused on accessing non-carbon nutrients such as organically bound nitrogen and phosphorus for the fungal and plant partners (Cairney \& Burke, 1998). As a result, the saprotrophic activity of ericoid mycorrhizal fungi could permit them to be effective competitors for nutrients with free-living heterotrophs, suppressing their activity to avoid microbial consumption of depolymerized substrates (Allison, 2005) and potentially limiting carbon mineralization activity (Lindahl et al., 2002). In contrast, sedge rhizospheres are substantially different environments due to an absence of mycorrhizas, deep root penetration into the peat, and abundance of oxygen supplied via aerenchyma, which may support aerobic microorganisms near root surfaces throughout the peat rhizosphere.

Plant functional group influences on peatland microbial community structure and function have previously been studied through field-based and mesocosm experiments contrasting oligotrophic bogs with minerotrophic fen peatlands (see Lin et al., 2012; Strakova et al., 2011; Myers et al., 2011; Peltoniemi et al., 2009; Kim et al., 2008; Jaatinen et al., 2007; Sowerby et al., 2005). However, bogs and fens fundamentally differ not only in plant functional group composition but also through hydrology, pH, nutrient availability, and soil chemistry (Bridgham et al., 1996) to such an extent that direct effects of plant functional groups are difficult to distinguish from myriad other environmental and physico-chemical conditions. In this study, we developed an experimental mesocosm facility to control for these environmental variables. We utilized oligotrophic bog monoliths originally composed of relatively equal distributions of sedge and ericaceous shrubs, and implemented vascular plant functional group manipulations to create either sedge dominant, ericaceous shrub dominant, or mixed dominance systems. To test our hypotheses, bacterial and archaeal communities were sequenced to determine changes in community composition following plant functional group manipulations. As microbial communities within peat monoliths were originally identical under the mixed plant 
system, any shift in community composition can be considered a direct result of the plant functional group manipulations.

The objective of this study was to quantitatively evaluate the initial shifts in microbial community structure in response to plant functional group manipulations. We hypothesized that the dominant vascular plant communities, sedges and ericaceous shrubs, would have different effects on peatland microbial community composition. We expected under high water table conditions an increase in the relative abundance of aerobic organic matter decomposers (e.g. taxa within Actinobacteria and Bacteroidetes phyla) and methanotrophic (methane oxidizing) bacteria (e.g. taxa within Alpha- and Gammaproteobacteria and Verrucomicrobia) throughout the sedge rhizosphere due to increased oxygen availability via aerenchyma. In contrast, the Ericaceae rhizosphere should experience an increase in the relative abundance of Acidobacteria (low $\mathrm{C}$ mineralization rates) and anaerobic-tolerant taxa as well as an increase in the relative abundance of methanogenic (methane producing) archaea at the deeper anoxic depths. Regardless of plant functional groups, we hypothesize a greater relative abundance of aerobic microorganisms at the more shallow $10-20 \mathrm{~cm}$ depth with increasing abundance of anaerobic taxa and archaea especially at the deeper 30-40 $\mathrm{cm}$ depth due to limitations in soil oxygen availability with increasing depth. Such changes in microbial community structure due to plant functional group manipulations are hypothesized to promote peat oxidation, carbon loss, and decreased methane production from sedge-dominated peatlands while Ericaceae peatlands would limit the effects of peat oxidation and organic carbon decomposition and support natural diffusion of methane to the atmosphere while limiting methane oxidation in the rhizosphere. 


\subsection{Methods and Materials}

\subsubsection{Site Description}

Peat monoliths were collected in close proximity to each other in May 2010 from an acidic ( $\mathrm{pH} 4.0$ ), oligotrophic bog in northeastern Minnesota $\left(47^{\circ} 07^{\prime} 05^{\prime} \mathrm{N}\right.$, 92 47'59'W, Meadowlands, MN). Vegetation included bryophytes (Sphagnum fuscum (Schimp.) Klinggr., S. magellanicum Brid., S. rubellum Wilson, Polytrichum strictum Brid.), sedges (Carex oligosperma Michx., Eriophorum angustifolium Honck.), and ericaceous shrubs (Andromeda glaucophylla Link., Chamaedaphne calyculata (L.) Moench., Kalmia polifolia Wang., Rhododendron groenlandicum Oeder., and Vaccinium oxycoccos L.). Peat monoliths were extracted from the treeless portion of the bog with a priori designation of relatively equal representation of both sedge and Ericaceae vascular plant cover (results not shown), while $E$. angustifolium was specifically avoided due to sparse and variable distribution.

\subsubsection{Experimental Design}

Twenty-four $1-\mathrm{m}^{3}$ peat monoliths were extracted from the bog, housed in Tefloncoated stainless steel mesocosm chambers, transported to Houghton Mich., and placed in the Houghton Mesocosm Facility at the USDA Forest Service Forestry Sciences Laboratory. Each mesocosm has been implemented with two $80 \mathrm{~cm}$ long temperature probes with 5 thermistors each to monitor vertical and horizontal temperature gradients, a dissolved oxygen sensor, a pressure transducer to continuously measure water table depth, with the latter linked to a proportional control valve attached to a porewater intake manifold to regulate and collect outflow water when water tables are sufficiently high to initiate flow. Beginning in July 2011, individual mesocosm chambers were randomly assigned one of the following plant functional group treatments: i.) "Unmanipulated" - sedge and Ericaceae left intact; 
ii.) "Sedge" - sedge left intact while Ericaceae removed; and iii.) "Ericaceae" Ericaceae left intact while sedge removed. Plant functional group treatments were replicated eight times and randomly assigned to establish the experimental design (3 plant functional group x 8 replicates, $N=24$ ).

To manipulate plant functional groups in July 2011, all above- and easily removable belowground biomass (buried stems) of Ericaceae was carefully removed while minimizing disturbance. To avoid significant peat disturbance only aboveground biomass of sedges was removed. Subsequent removals of regrown targeted biomass were implemented by clipping weekly throughout the growing season to ensure complete removal of the targeted plant communities. Along with plant functional group treatments, each mesocosm chamber was assigned either a "high" or "low" water table treatment with seasonal profiles based on typical low variability, high minimum water table years (high treatment), and typical high variability, low water table years (low treatment) derived from the almost 50 year record of precipitation and water tables at the Marcell Experimental Forest (Kolka et al., 2011). In year 1 of the vegetation treatments (2011, year of present study) water table manipulations were kept to a minimum (approximately $5 \mathrm{~cm}$ difference between high and low water treatments during summer) to permit full vegetation recovery and were not considered as a treatment combination (e.g. Sedge - High water table) in the experimental design until 2012.

\subsubsection{Peat Sampling, Biogeochemical Properties, and Enzyme Assays}

An individual peat core $(0-80 \mathrm{~cm}$ depth; $3 \mathrm{~cm}$ diameter) was collected from each mesocosm chamber $(N=24)$ over a two-week sampling period spanning August 31 to September 13, 2011. These cores represented the vertical peat soil profile approximately two months following plant functional group manipulations. Each core was partitioned into $10 \mathrm{~cm}$ vertical increments, placed in labeled Ziploc bags, 
and immediately stored at $-80^{\circ} \mathrm{C}$ to preserve microbial nucleic acids for future analysis. The $10-20 \mathrm{~cm}$ and $30-40 \mathrm{~cm}$ vertical increments were utilized for all subsequent microbial analyses.

Porewater samples were collected at the same depths as the peat samples $(20 \mathrm{~cm}$ and $40 \mathrm{~cm}$ ) by Aleta Daniels (graduate student - Michigan Tech) using piezometers. Laboratory techniques for analyzing dissolved organic carbon (DOC) and total dissolved nitrogen (TDN) concentrations were described previously using high temperature catalytic oxidation techniques (Olefeldt \& Roulet, 2012) with modifications specific for this study introduced by Evan Kane (personal communication). In addition, two optical properties indicating alterations in DOC composition were analyzed. The first property, specific ultraviolet absorbance $\left(\mathrm{SUVA}_{254}\right)$, was calculated by normalizing UV absorbance at $254 \mathrm{~nm}$ against DOC concentrations. The $\mathrm{SUVA}_{254}$ index is reported to increase linearly with measured DOC aromaticity (Weishaar et al., 2003). The second property, $E_{2}: E_{3}$, is the UV absorbance ratio between $254 \mathrm{~nm}$ and $365 \mathrm{~nm}$. The $E_{2}: E_{3}$ ratio decreases as molecular size increases allowing for an estimation of dissolved organic matter (DOM) size (De Haan \& De Boer, 1987).

Extracellular enzyme assays were conducted using methods described by Saiya-Cork et al. (2002), with modifications for organic soil. All enzyme assays were conducted within 4 hours of peat core collection on a vertical split of the $10-20 \mathrm{~cm}$ core increment. Enzyme assays were not conducted on the $30-40 \mathrm{~cm}$ depth samples. In brief, bulk peat samples from the 10-20 $\mathrm{cm}$ depth were prepared in suspensions by adding $1.0 \mathrm{~g}$ (wet weight) peat to $125 \mathrm{ml}$ of deionized water and shaken for two minutes to homogenize thoroughly. Peat suspensions were stirred continuously on a magnetic stir plate while $200 \mu \mathrm{L}$ aliquots were dispensed into 96-well microplates with eight replicate wells per sample per assay. The peat suspensions were assayed for two oxidative enzyme activities and three hydrolytic enzyme activities involved 
with carbon, sulfur, and phosphorous cycling (Table 1). All hydrolytic assays were analyzed fluorimetrically with $365 \mathrm{~nm}$ excitation and $450 \mathrm{~nm}$ emission filters, while oxidative assays were measured spectrophotometrically by quantifying absorbance at $450 \mathrm{~nm}$. Both fluorimetric and absorbance measurements were performed on a SpectraMax M2 plate reader (Molecular Devices, Sunnyvale, California). All subsequent plating conditions were followed according to Saiya-Cork et al. (2002) with the following modifications: eight replicate wells for each blank, negative control, and quench standard, and all microplates were incubated in the dark at room temperature for 3 hours or 24 hours for hydrolytic or oxidative assays, respectively. Also, $50 \mu \mathrm{L}$ of $5 \mathrm{mM} \mathrm{L-3,4-dihydroxyphenylalanine} \mathrm{(L-DOPA)} \mathrm{were} \mathrm{added} \mathrm{to} \mathrm{each}$ sample well for measuring phenol oxidase and peroxidase enzyme activities as modified from $25 \mathrm{mM}$ L-DOPA for ease of dissolving substrate in deionized water. Comparison of measured enzyme activity between $5 \mathrm{mM}$ and $25 \mathrm{mM}$ L-DOPA showed no statistical differences (results not shown). Potential oxidative enzyme activity for peat suspensions were expressed as $1 \mu \mathrm{mol}$ of L-DOPA substrate oxidized $\mathrm{h}^{-1} \mathrm{~g}^{-1}$ dry mass. Potential hydrolytic enzyme activity for peat suspensions were expressed as $1 \mathrm{nmol}$ of substrate consumed $\mathrm{h}^{-1} \mathrm{~g}^{-1}$ dry mass.

\subsubsection{DNA Extraction and Illumina Sequencing}

Microbial DNA extractions were carried out at the Forestry Sciences Laboratory in Houghton, Michigan at two depths from peat cores collected in September 2011. In brief, all peat core increments from both the 10-20 cm depth and 30-40 $\mathrm{cm}$ depth were removed from $-80^{\circ} \mathrm{C}$ storage, suspended in liquid nitrogen, fragmented by hand in mortar and pestle, re-suspended in liquid nitrogen, then finely ground in an electric coffee grinder prior to DNA extractions (sterilized between samples). Following homogenization, total genomic DNA was extracted from $0.5 \mathrm{~g}$ peat soil using a MoBio PowerSoil ${ }^{\circledR}$ DNA Isolation kit following the manufacturer's instructions (MoBio Laboratories Inc., Carlsbad, California). Extracted DNA quantity and quality 
visualizations were performed on 2:1\% agarose gel through electrophoresis for 10-20 $\mathrm{cm}$ depth (Supplemental Figure S1) and 30-40 cm depth (Supplemental Figure S2). Isolated DNA samples were purified using a MoBio PowerClean ${ }^{\circledR}$ DNA Clean-Up kit following manufacturer's instructions (MoBio Laboratories Inc., Carlsbad, California) and stored in TE buffer solution $\mathrm{pH}$ 7.6. DNA quantitation was assessed on a NanoDrop 1000 spectrophotometer (Thermo Scientific Inc., Waltham, Massachusetts) to ensure sample quantities exceeded $10 \mathrm{ng} \mu \mathrm{l}^{-1}$ (results not shown). All purified DNA samples were sent to U.S. Department of Energy Joint Genome Institute (JGI) in Walnut Creek, California for amplification and iTAG 16S V4 region sequencing (see Caporaso et al., 2011) on the Illumina MiSeq platform.

\subsubsection{Illumina Sequencing Analysis Pipeline}

All 16S rDNA amplicons (iTags) were sequenced on the Illumina MiSeq instrument with a $2 \times 250$ bp reads configuration resulting in roughly 4 million sequenced forward reads and 4 million reverse reads. Julien Tremblay performed the following methods at the Joint Genome Institute and provided all method descriptions. In brief, all unpaired reads following sequencing were discarded and all remaining reads were trimmed to $165 \mathrm{bp}$. Reads were assembled (overlapping paired assembly) with FLASH software (Magoc \& Salzberg, 2011) and primer sequences were removed from the assembled reads. Assembled reads were trimmed from both 5' and 3' ends using a $20 \mathrm{bp}$ sliding window quality threshold having a mean quality of 30 . The trimmed assembled reads were filtered for quality where all reads having more than 10 nucleotides below quality 15 were discarded. Remaining reads were referred to as filtered reads and were clustered into operational taxonomic units (OTUs) at 97\% similarity with JGI's in-house clustering algorithm (SeqObs). No denoising or chimera removal step was implemented, but singleton OTUs were removed prior to downstream analyses. Remaining OTUs were analyzed for taxonomic distribution using QIIME version 1.6.0 (Caporaso et al., 2010) where OTUs were classified with 
the Ribosomal Database Project (RDP) classifier using a JGI in-house training set containing the complete Greengenes database supplemented with eukaryotic sequences from the Silva databases and a customized set of mitochondria and chloroplasts $16 \mathrm{~S}$ sequences.

\subsubsection{Statistical Analyses}

Bacterial and archaeal richness and evenness were calculated in QIIME version 1.6.0 based on their original OTU tables rarefied to 6,688 bacterial sequence reads and 23 archaeal sequence reads per sample, respectively. Microbial diversity was expressed as Chao 1 richness and equitability evenness $(1=$ complete equitability $)$. Pairwise sample dissimilarities of microbial community structure were calculated as BrayCurtis distances with 1,000 permutations, and visualized using principal coordinate analysis (PCoA) ordination. Environmental effects (e.g. porewater chemistry, relative percentage of vegetation, and extracellular enzyme activity) on microbial community variation were evaluated within each depth through the envfit function of the vegan package in $\mathrm{R}$ (see Oksanen et al., 2011) with 1,000 permutations using the bray-curtis distance matrix derived for PCoA. Plant functional group and soil depth effects on bacterial and archaeal taxonomic diversity at the phylum and order level, respectively, were calculated using multivariate analysis of variance (MANOVA) in R. Post-hoc tests utilizing Tukey's Honestly Significant Difference were conducted on variables considered significant $(\mathrm{p}<0.05)$ through MANOVA analysis to determine which treatment combinations created significant differences. OTU category significance tests were performed in QIIME on bacterial and archaeal OTUs utilizing analysis of variance (ANOVA) for categorical variables such as sampling depth and plant functional group, while Pearson correlations were utilized for continuous variables including sedge percent cover, $\mathrm{pH}$, and water table. 


\subsection{Results}

\subsubsection{Bacterial and Archaeal Sampling Diversity}

The Illumina sequencing bacterial data set contained 1,534,582 total read sequences with an average $34,101 \pm 15,608$ reads per sample, which clustered into 6,218 OTUs at the $97 \%$ sequence similarity level. Likewise, the archaeal data set contained 9,713 total read sequences with an average $215 \pm 178$ reads per sample, which clustered into 44 OTUs at the $97 \%$ sequence similarity level. Bayesian classification indicated $99.37 \%$ of total read sequences were bacteria and $0.63 \%$ of total read sequences were archaea. All OTU-based analyses were performed on the original OTU table rarefied to the lowest total sample sequence read for both bacteria (6,688 reads) and archaea (23 reads) to minimize the effects of uneven sampling effort in comparing diversity across samples (Table 2).

\subsubsection{Bacterial and Archaeal Species Richness and Evenness}

The rank abundance distributions for bacteria showed strong dominance of a few OTUs with a long tail of rare OTUs irrespective of plant functional group treatment or depth. Rank abundance for archaea was similar, indicating 12 OTUs representing $1 \%$ or greater relative abundance followed by $\sim 20-30$ OTUs each representing less than $1 \%$ of total relative abundance (Figure 1). During the two week peat coring process in September 2011, water table levels remained above the 10-20 cm sampling depth (Figure 2) indicating all samples collected should have been experiencing anaerobic soil conditions. Statistical analyses of bacterial species richness indicated no significant differences between plant functional groups or depth but evenness was significantly different between sampling depths $(\mathrm{p}=0.009)$ with increased equitability within the 30-40 cm depth (Table 2). Archaeal richness and evenness was not significantly influenced by depth or plant functional group treatments. These results 
suggests that greater bacterial species evenness at the deeper $30-40 \mathrm{~cm}$ depth indicates greater homogeneity, and confirms that the bacterial community was dominated by a select number of OTUs as alluded to in the rank abundance distribution.

\subsubsection{Bacterial and Archaeal Taxonomic Classification}

Bacterial OTUs were assigned to 15 phyla (with Proteobacteria separated into 5 classes) while archaeal OTUs were assigned to 2 phyla with all subsequent analyses comparing 9 orders within 6 classes of the 2 phyla (Table 3). Across all treatment combinations, dominant phyla included (in order of decreasing abundance) Acidobacteria, Bacteroidetes, Alphaproteobacteria, Gammaproteobacteria, Cyanobacteria, Firmicutes, Verrucomicrobia, Actinobacteria, Planctomycetes, and Deltaproteobacteria. The remaining 7 phyla (and 3 Proteobacteria classes) combined represented less than $5 \%$ of total community composition and included (in order of decreasing abundance) Chlamydiae, Betaproteobacteria, Proteobacteria unclassified, Spirochaetes, Nitrospirae, Tenericutes, Armatimonadetes, Chloroflexi, Epsilonproteobacteria, and Fusobacteria. $18 \%$ of all bacterial OTUs were not classified beyond domain.

Overall, the taxonomic distribution of OTUs within the bog soils indicated certain significant changes in community composition based on both depth (Figure 3) and plant functional group treatments (Figure 4). MANOVA results indicated bacterial community composition significantly differed between the $10-20 \mathrm{~cm}$ and $30-40 \mathrm{~cm}$ depths and also differed within depths by plant functional group manipulations. Acidobacteria was the dominant phylum throughout the bog soils representing 39\% of total community composition and significantly differed between depths $(p<0.0001)$ with greatest relative abundance within the $30-40 \mathrm{~cm}$ depth and also differed between sedge and Ericaceae treatments $(\mathrm{p}=0.020)$ with greatest relative abundance within 
sedge treatments. Likewise, Bacteroidetes, which represented $11 \%$ of total bacterial composition, differed between depths $(\mathrm{p}<0.0001)$ with greatest relative abundance within the 10-20 cm depth and also differed between sedge and Ericaceae treatments $(p=0.012)$ with greatest relative abundance within the Ericaceae treatments. However, Acidobacteria and Bacteroidetes did not statistically differ between sedge and unmanipulated treatments $(\mathrm{p}=0.125 ; \mathrm{p}=0.244$, respectively) or Ericaceae and unmanipulated treatments $(\mathrm{p}=0.648 ; \mathrm{p}=0.313$, respectively) suggesting sedge and ericaceous plant communities are driving opposite effects on both Acidobacteria and Bacteroidetes abundance especially at the $10-20 \mathrm{~cm}$ depth.

Alphaproteobacteria ( $9 \%$ of total bacteria), Gammaproteobacteria (6\% of total bacteria), and Verrucomicrobia (4\% of total bacteria) differed only between sampling depths (all $\mathrm{p}<0.05$ ) but were not significantly influenced by plant functional groups or the interaction between depth and plant functional group treatments. Specifically, the 10-20 cm depth had higher relative abundance of Alpha- and Gammaproteobacteria while the $30-40 \mathrm{~cm}$ depth had higher relative abundance of Verrucomicrobia.

A thorough examination of methane oxidizing species indicated that our study included the following taxa: Alphaproteobacteria Methylocella spp. of the family Beijerinckiaceae, Methylocystis spp. and Methylosinus spp. of the family Methylocystaceae; Gammaproteobacteria Methylococcus spp. and Methylomonas spp. of the family Methylococcaceae; and Verrucomicrobia Methylacidiphilum spp. of the family Methylacidiphilaceae (see Supplemental Figure S3). Increasing depth had a significant positive impact on the relative abundance of methanotrophs only in the unmanipulated plant functional group treatment $(p<0.05)$, but trends suggested a greater abundance of these taxa exists within sedge treatments compared to Ericaceae treatments in the 10-20 cm depth (Figure 12). 
Dominant archaeal communities included members of the methanogenic Euryarchaeota such as Methanobacteriales (23\%), Methanomicrobiales (11\%), Methanosarcinales $(2 \%)$, and Methanocellales $(<1 \%)$ with a large proportion of unclassified Euryarchaeota (22\%) (Table 3). Non-methanogenic Crenarchaeota included Cenarchaeales (28\%), Thermoproteales $(<1 \%)$, and Nitrososphaerales $(<1 \%)$. Over $5 \%$ of all archaea sequenced were unclassified beyond domain. Cenarchaeales was the dominant non-methanogenic Crenarchaeota across the majority of treatments.

Although total archaeal abundance was low, there were considerable variations between depths (Figure 5) and marginally significant differences between plant functional group treatments (Figure 6). The proportion of methanogenic Methanobacteriales at the 10-20 cm depth was more than double the $30-40 \mathrm{~cm}$ depth $(\mathrm{p}=0.002)$ but a large proportion of Euryarchaeota were unclassified at the $30-40 \mathrm{~cm}$ depth compared to the $10-20 \mathrm{~cm}$ depth $(\mathrm{p}<0.0001)$ (see Supplemental Figure S4). Likewise, Methanomicrobiales was 7 times greater at the 10-20 cm depth compared to the $30-40 \mathrm{~cm}$ depth $(\mathrm{p}=0.001)$. The relative recovery of methanogens overall was influenced by sampling depth with greatest relative abundance within the $10-20 \mathrm{~cm}$ depth, while plant functional groups appeared to have no significant influence on relative recovery (Figure 13). It should be noted that the Euryarchaeota member Halobacteriales was initially 17 times greater in the Ericaceae treatment at the 10-20 $\mathrm{cm}$ depth compared to all other treatment combinations, which was a direct result of an outlier community in one of the replicate mesocosms (i.e. Bin 13, Ericaceae treatment, $10-20 \mathrm{~cm}$ depth consisted of $83 \%$ Halobacteriales) but this sample was removed from all analyses as it was believed to be a contamination issue possibly incorporated during the sequencing process ( $\mathrm{S}$. Tringe, personal communication). 


\subsubsection{Significant Bacterial and Archaeal OTUs}

An OTU significance test based on analysis of variance (ANOVA) between sampling depths was performed in QIIME on the top 100 most abundant bacterial OTUs and indicated that 46 of those OTUs had a significant preference for a particular depth after Bonferroni correction (Supplemental Table S1). Within archaea, 6 of 46 OTUs were found to have significant preferences by depth following Bonferroni correction (Supplemental Table S2). Heatmaps displayed visual differences in the relative abundance of the top 100 bacterial OTUs by treatment and depth combination (Figure 7) and all archaeal OTUs by treatment and depth combination (Figure 8).

After determining significant differences between sampling depths, further OTU significance tests were performed within each depth. An OTU significance test based on ANOVA between plant functional groups was performed within both sampling depths for bacteria and archaea, but following Bonferroni corrections, no OTUs were found to have significant plant functional group preferences (results not shown). Pearson correlations were calculated utilizing sedge percent cover, $\mathrm{pH}$, and water table on bacterial and archaeal OTUs within both sampling depths but also found no significant results within any treatment combination (results not shown).

\subsubsection{Community Comparison Across Plant Functional Groups and Depth}

Bacterial and archaeal communities separated by depth along the first axis (PCO1) of the principal coordinate analysis based on Bray-Curtis similarity (Figures 9A; 9B). PCO1 for bacteria explained $50.37 \%$ of total variation while PCO1 for archaea explained $33.92 \%$ of total variation. The second axis (PCO2) of the PCoA separates bacterial and archaeal communities by plant functional groups. PCO2 for bacteria explained $10.94 \%$ of total variation while PCO2 for archaea explained $13.69 \%$ of 
total variation. Depth appears to be the dominant factor driving microbial community variation, however, within the $10-20 \mathrm{~cm}$ depth it appears that microbial communities respond differently between sedge and Ericaceae treatments. Taxonomic variation was calculated and plotted alongside plant functional group by depth treatments on the PCoA to further illustrate their effects on altering microbial community composition. Within bacteria, Cyanobacteria and Bacteroidetes appear to have shifted towards the $10-20 \mathrm{~cm}$ depth and their relative recovery increased the most within the unmanipulated and Ericaceae treatments. Firmicutes was the only phylum that had a strong preference for the $30-40 \mathrm{~cm}$ depth and all remaining phyla had no preference for either depth or any particular plant functional group treatment. For the archaea, methanogenic Methanobacteriales and Methanomicrobiales were most abundant at the 10-20 $\mathrm{cm}$ depth within the unmanipulated and sedge treatments. All subsequent orders except Cenarchaeales increased in abundance in the 30-40 cm depth with no noticeable preference under sedge or Ericaceae treatments.

\subsubsection{Environmental Influence on Bacterial and Archaeal Community Composition}

A combination of data including $\mathrm{pH}$, porewater biogeochemistry, optical properties of DOC, water table levels, relative percentage of vegetation species, and extracellular enzyme activities (Table 4) were incorporated into an envfit analysis against OTU distributions for both bacteria and archaea to better understand correlations between microbial community composition and environmental factors. Results from the envfit analysis (Table 5) for bacteria at the $10-20 \mathrm{~cm}$ depth indicated that the relative percentage of Carex oligosperma $(\mathrm{p}=0.001)$ along with DOC concentrations ( $\mathrm{p}=0.040)$, the ratio of $\mathrm{E}_{2}: \mathrm{E}_{3} \quad(\mathrm{p}=0.034)$, and sulfatase activity $(\mathrm{p}=0.002)$ all significantly correlated with community variation (Figure 10A). Likewise, the relative percentage of Vaccinium oxycoccos $(\mathrm{p}=0.085)$, the ratio of $\mathrm{SUVA}_{254}$ $(\mathrm{p}=0.099)$, and $\beta$-glucosidase activity $(\mathrm{p}=0.058)$ were all marginally significantly correlated with community variation at the $10-20 \mathrm{~cm}$ depth (Figure 10A). However, 
at the $30-40 \mathrm{~cm}$ depth, no environmental factor significantly correlated with bacterial community variation (Figure 10B).

Archaeal community variation at the $10-20 \mathrm{~cm}$ depth was significantly correlated to peroxidase $(\mathrm{p}=0.011)$, sulfatase $(\mathrm{p}=0.026)$, and $\beta$-glucosidase $(\mathrm{p}=0.018)$ activities, but no other environmental variables had a significant correlation except water table $(\mathrm{p}=0.082$ ), which was marginally significant (Figure 11A). At the $30-40 \mathrm{~cm}$ depth, archaeal community variation is not significantly correlated to any environmental factor measured in this study (Figure 11B). The combined variation of axes PCO1 and $\mathrm{PCO} 2$ for bacteria at the $10-20 \mathrm{~cm}$ depth explained $59.97 \%$ of total community variation, while combined axes for bacteria at the $30-40 \mathrm{~cm}$ depth explained $76.83 \%$ of total community variation. Likewise, combined axes for archaea at the $10-20 \mathrm{~cm}$ depth explained $46.09 \%$, while the $30-40 \mathrm{~cm}$ depth explained $61.77 \%$ of total community variation. 


\subsection{Discussion}

\subsubsection{Plant Functional Group Effects on Bacterial and Archaeal Community Composition}

Acidic, oligotrophic bogs were originally considered sterile (Waksman and Stevens, 1929) but have since been found to contain a diverse assemblage of microorganisms. Peat monoliths in our mesocosm experiment were comprised of Sphagnum-derived peats with low $\mathrm{pH}$ and contained bacterial and archaeal assemblages observed in acidtolerant bogs (Dedysh et al., 2006) rather than fen systems dominated by neutral pH phylotypes (Lin et al., 2012). Bacterial community composition was dominated by Acidobacteria species regardless of plant functional group treatments or soil depth with the most abundant OTU classified taxonomically as most closely related to Terriglobus roseus (7\% relative abundance) of the family Acidobacteriaceae. Recent molecular studies have identified that Acidobacteria are best suited to acidic, lownutrient conditions, being long-lived with the ability to tolerate fluctuations in soil hydration, and function in plant polymer hydrolysis utilizing carbon sources including hemicellulose, cellulose, and chitin (Ward et al., 2009).

Plant functional groups appear to influence certain phyla only within the more shallow 10-20 $\mathrm{cm}$ depth, indicating plant traits may have more direct influence on bacterial and archaeal community composition closer to the peat surface. Noticeable differences observed between sedge and ericaceous shrub treatments within the 10-20 cm depth suggest that Ericaceae may suppress the relative abundance of Acidobacteria and promote increased abundance of Bacteroidetes and Gammaproteobacteria taxa. Bacteroidetes species are hypothesized to function mainly in plant polymer hydrolysis (Tveit et al., 2012) and are known to respond in a predictable manner to changes in carbon availability (Fierer et al., 2007). In contrast, sedge treatments were found to promote increased homogeneity with strong 
dominance by Acidobacteria. With time, plant functional groups may begin to influence microbial communities at deeper peat depths, but as of two months following vegetation manipulations there has yet to be any significant influences attributed to plant functional group composition.

Certain species of Alpha-, and Gammaproteobacteria as well as Verrucomicrobia are linked to methane oxidizing capabilities under aerobic soil conditions (Dedysh, 2009), which may explain the trends showing increased abundance within the more shallow 10-20 $\mathrm{cm}$ depth under sedge treatments whose aerenchyma are supplying the anaerobic peat with increase oxygen availability. Due to high water table conditions at the time of sampling, our chosen sampling depths may be experiencing oxygen limitation within Ericaceae treatments, subsequently limiting the relative abundance of aerobic methane oxidizing bacterial communities initially hypothesized. In the absence of aerenchyma and ebullition, methane created under anaerobic soil conditions must naturally diffuse up through the aerobic layers near the peat surface (0-10 $\mathrm{cm}$ depth at time of study) prior to atmospheric release, becoming susceptible to oxidation and subsequent conversion to carbon dioxide (Schlesinger, 1997) by methane oxidizing bacteria. However, current water table conditions at the $10-20 \mathrm{~cm}$ depth appear to limit these naturally occurring methane oxidation processes. Subsequently, an increase in available methane under sedge-mediated aerobic rhizosphere conditions near the peat surface may encourage the growth of methane oxidizing bacteria and promote oxidizing redox conditions.

Anaerobic fermentation processes are prevalent functional pathways for carbon mineralization (Tveit et al., 2012), whose waste products via microbial metabolism become the substrates for methanogenic archaea to carry out both hydrogenotrophic and acetoclastic methanogenesis (Brauer et al., 2006; Whalen, 2005; Horn et al., 2003). A lack of distinction in the relative abundance of microbial species between plant functional group treatments within the $30-40 \mathrm{~cm}$ depth may be the result of 
abrupt changes in aboveground plant biomass, as the system has not regained equilibrium with the environmental conditions. Further work is needed to fully gauge the sustained effects plant functional groups may have on influencing bacterial community structure and function throughout the peat profile.

The dominant methanogenic Euryarchaeota included Methanomicrobiales and Methanobacteriales especially in the 10-20 cm depth. Both of these archaeal orders are considered hydrogenotrophic, producing $\mathrm{CH}_{4}$ from $\mathrm{H}_{2}$ and $\mathrm{CO}_{2}$, and their high abundance correlates well with previous studies claiming hydrogenotrophic methanogenesis is the dominant pathway in oligotrophic bogs and other northern peatlands (Horn et al., 2003; Keller and Bridgham, 2007). A large proportion of unclassified Euryarchaeota were observed at the 30-40 cm depth and may be associated with any number of different archaeal orders found in acidic bogs, making predictions about plant functional group influences on archael community composition difficult to discern. In addition, these unclassified Euryarchaeota may represent novel lineages not yet described in peatland soils and should be further investigated.

A previous peatland microbial sequencing study (see Lin et al., 2012) found members of Methanosarcinales were the dominant methanogenic archaea in their bog soils. Methanosarcinales are metabolically more diverse than Methanomicrobiales and Methanobacteriales and can carry out acetoclastic, hydrogenotrophic, and methylotrophic methanogenesis (Garcia et al., 2000). Our results indicated that Methanosarcinales were present in relatively low abundances throughout the peat profile, suggesting that acetoclastic methanogenesis was not a dominant methanogenic pathway within these peat soils. The relatively low abundance of Methanosarcinales in our study may be explained by the increased abundance of sulfate reducing bacteria (e.g. Deltaproteobacteria taxa) and their seasonal influences on acetate concentrations in the peat soil. Shannon and White (1996) found that 
acetate concentrations in bog porewater began to decline in late summer and early fall as sulfate reducers consumed the accumulated acetate. Further analysis of the competition between sulfate reducers and acetoclastic archaea for porewater acetate in early September 2011 could explain the relatively low abundances of Methanosarcinales observed in this study.

\subsubsection{Limitations of DNA-based Sequencing Studies}

Initial changes in the relative recovery of both bacterial and archaeal community composition were observed only in the 10-20 cm depth. These changes may be the direct result of plant functional group manipulations and their subsequent effects on peat soil conditions, but may also be explained in part by the techniques used in this study. High throughput sequencing of extracted soil microbial DNA represents total community composition as it cannot distinguish between viable and non-viable cells (van Elsas and Boersma, 2011) nor dormant versus active cells (Lennon and Jones, 2011). Sequencing data from this study might be representative of microbial community composition prior to plant functional group manipulations as dormant microorganisms can maintain low metabolic activity until environmental conditions become favorable (Jones and Lennon, 2010) and DNA from non-viable microbes can persist in soil environments for considerable periods of time. As such, this study may lack the resolution necessary to accurately quantify the immediate changes in microbial structure following plant community changes. Future studies should strive to sequence both DNA and RNA from environmental samples to capture total community composition and active community composition, respectively. An RNAbased sequencing analysis may provide greater insight into the immediate changes in microbial community structure following plant functional group manipulations as only the active microbial communities at the time of sampling would be detected. 


\subsubsection{Conclusions}

This study revealed the initial response of bacterial and archaeal community composition within an oligotrophic bog to changes in plant functional group dominance and demonstrated distinct microbial responses between sedge and Ericaceae treatments as well as changes in peat depth. Our results suggest that the more shallow 10-20 $\mathrm{cm}$ depth is experiencing more pronounced changes in both bacterial and archaeal community structure with the dominant vascular plant functional groups, sedges and Ericaceae, driving opposing effects on microbial community abundance. Sedge-dominated treatments appear to promote aerobic methane oxidizing bacterial communities as a result of increased soil oxygen availability supplied via aerenchyma, while also promoting decreased anaerobic microbial heterogeneity overall. In contrast, Ericaceae treatments under high water table conditions may experience an increase in the relative abundance of anaerobic microbial communities, which suggests that under high water tables Ericaceae may have less direct influence on regulating atmospheric methane flux and possibly encourage decreased plant-based carbon mineralization and function as atmospheric carbon sinks through decreased decomposition. 


\subsection{Acknowledgements}

I thank Carley Kratz from Michigan Technological University for initial guidance with molecular techniques and extracellular enzyme assays. I thank Lynette Potvin and Joe DesRochers from the USDA Forest Service Northern Research Station for technical assistance. I thank Evan Kane and Aleta Daniels from Michigan Technological University for their contributions to porewater chemistry methods and data collection. I also thank Julien Tremblay from the DOE Joint Genome Institute for methods describing the JGI Illumina analysis pipeline. All sequencing services were provided by the DOE Joint Genome Institute, Walnut Creek, California (http://www.jgi.doe.gov/). Our research was funded by the National Science Foundation grant DEB-1146149 and by the USDA Forest Service, Northern Research Station.

\subsection{Literature Cited}

1. Allison, S.D. 2005. Cheaters, diffusion and nutrients constrain decomposition by microbial enzymes in spatially structured environments. Ecology Letters 8, 626635.

2. Andersen, R., Chapman, S.J., Artz, R.R.E. 2012. Microbial communities in natural and disturbed peatlands: A review. Soil Biology and Biochemistry 57, 979-994.

3. Artz, R.R.E. 2009. Microbial community structure and carbon substrate use in northern peatlands. In: Baird, A.J., Belyea, L.R., Comas, X., Reeve, A.S., Slater, L.D., Eds. Carbon Cycling in Northern Peatlands. American Geophysical Union, 111-129. 
4. Artz, R.R.E., Anderson, I.C., Chapman, S.J., Hagn, A., Schloter, M., Potts, J.M., Campbell, C.D. 2007. Changes in fungal community composition in response to vegetational succession during the natural regeneration of cutover peatlands. Microbial Ecology 54, 508-522.

5. Bonfante, P., Genre, A. 2010. Mechanisms underlying beneficial plant-fungus interactions in mycorrhizal symbiosis. Nature Communications 1, 1-11.

6. Borga, P., Nilsson, M., Tunlid, A. 1994. Bacterial communities in peat in relation to botanical composition as revealed by phospholipid fatty acid analysis. Soil Biology and Biochemistry 26, 841-848.

7. Brauer, S.L., Yashiro, E., Ueno, N.G., Yavitt, J.B., Zinder, S.H. 2006. Characterization of acid-tolerant $\mathrm{H}_{2} / \mathrm{CO}_{2}$-utilizing methanogenic enrichment cultures from an acidic peat bog in New York State. FEMS Microbiology Ecology 57, 206-216.

8. Breeuwer, A., Robroek, B.J.M., Limpens, J., Heijmans, M.M.P.D., Schouten, M.G.C., Berendse, F. 2009. Decreased summer water table depth affects peatland vegetation. Basic and Applied Ecology 10, 330-339.

9. Bridgham, S.D., Pastor, J., Janssens, J.A., Chapin, C., Malterer, T.J. 1996. Multiple limiting gradients in peatlands: a call for a new paradigm. Wetlands 16, 45-65.

10. Cadillo-Quiroz, H., Yavitt, J.B., Zinder, S.H., Thies, J.E. 2009. Diversity and community structure of archaea inhabiting the rhizoplane of two contrasting plants from an acidic bog. Microbial Ecology 59, 757-767. 
11. Cairney, J.W.G., Burke, R.M. 1998. Extracellular enzyme activities of the ericoid mycorrhizal endophyte Hymenoscyphus ericae (Read) Korf \& Kernan: their likely roles in decomposition of dead plant tissue in soil. Plant and Soil 205, $181-192$.

12. Caporaso, J.G., Kuczynski, J., Stombaugh, J., Bittinger, K., Bushman, F.D., Costello, E.K., Fierer, N., Peña, A.G., Goodrich, J.K., Gordon, J.I., Huttley, G.A., Kelley, S.T., Knights, D., Koenig, J.E., Ley, R.E., Lozupone, C.A., McDonald, D., Muegge, B.D., Pirrung, M., Reeder, J., Sevinsky, J.R., Turnbaugh, P.J., Walters, W.A., Widmann, J., Yatsunenko, T., Zaneveld, J., Knight, R. 2010. QIIME allows analysis of high-throughput community sequencing data. Nature Methods 7, 335-336.

13. Caporaso, J.G., Lauber, C.L., Walters, W.A., Berg-Lyons, D., Lozupone, C.A., Turnbaugh, P.J., Fierer, N., Knight, R. 2011. Global patterns of 16S rRNA diversity at a depth of millions of sequences per sample. Proceedings of the National Academy of Sciences of the United States of America 108, 4516-4522.

14. Clymo, R.S. 1984. The limits to peat bog growth. Philosophical Transactions of the Royal Society of London. B, Biological Sciences 303, 605-654.

15. Clymo, R.S., Turunen, J., Tolonen, K. 1998. Carbon accumulation in peatland. Oikos 368-388.

16. Crum, H. 1991. A Focus on Peatlands and Peat Mosses. $4^{\text {th }}$ Ed. The University of Michigan Press, Ann Arbor.

17. Dedysh, S.N. 2009. Exploring methanotroph diversity in acidic northern wetlands: molecular and cultivation-based studies. Microbiology 78, 655-669. 
18. Dedysh, S.N., Panikov, N.S., Tiedje, J.M. 1998. Acidophilic methanotrophic communities from Sphagnum peat bogs. Applied and Environmental Microbiology 64, 922-929.

19. De Haan, H., De Boer, T. 1987. Applicability of light absorbance and fluorescence as measures of concentration and molecular size of dissolved organic carbon in humic Lake Tjeukemeer. Water Research 21, 731-734.

20. Dinsmore, K.J., Billett, M.F., Skiba, U.M., Rees, R.M., Drewer, J., Helfter, C. 2010. Role of the aquatic pathway in the carbon and greenhouse gas budgets of a peatland catchment. Global Change Biology 16, 2750-2762.

21. Farrick, K.K., Price, J.S. 2009. Ericaceous shrubs on abandoned block-cut peatlands: implications for soil water availability and Sphagnum restoration. Ecohydrology 2, 530-540.

22. Fierer, N., Bradford, M.A., Jackson, R.B. 2007. Toward an ecological classification of soil bacteria. Ecology 88, 1354-1364.

23. Fisk, M., Ruether, K.F., Yavitt, J.B. 2003. Microbial activity and functional composition among northern peatland ecosystems. Soil Biology and Biochemistry 35, 591-602.

24. Garcia, J.L., Patel, B.K.C., Ollivier, B. 2000. Taxonomic phylogenetic and ecological diversity of methanogenic archaea. Anaerobe 6, 205-226.

25. Gorham, E. 1991. Northern peatlands: role in the carbon cycle and probable responses to climatic warming. Ecological Applications 1, 182-195. 
26. Groisman, P.Y., Knight, R.W., Easterling, D.R., Karl, T.R., Hegerl, G.C., Razuvaev, V.N. 2005. Trends in intense precipitation in the climate record. Journal of climate $18,1326-1350$.

27. Hilbert, D.W., Roulet, N.T., Moore, T.R. 2000. Modelling and analysis of peatlands as dynamical systems. Journal of Ecology 88, 230-242.

28. Holzapfel-Pschorn, A., Conrad, R., Seiler, W. 1986. Effects of vegetation on the emission of methane from submerged paddy soil. Plant and Soil 92, 223-233.

29. Horn, M.A., Matthies, C., Küsel, K., Schramm, A., Drake, H.L. 2003. Hydrogenotrophic methanogenesis by moderately acid-tolerant methanogens of a methane-emitting acidic peat. Applied and Environmental Microbiology 69, 7483.

30. Inderjit, Mallik, A.U. 2002. Can Kalmia angustifolia interference to black spruce (Picea mariana) be explained by allelopathy? Forest Ecology and Management $160,75-84$.

31. Jaatinen, K., Fritze, H., Laine, J., Laiho, R. 2007. Effects of short- and long-term water-level drawdown on the populations and activity of aerobic decomposers in a boreal peatland. Global Change Biology 13, 491-510.

32. Joanisse, G.D., Bradley, R.L., Preston, C.M., Munson, A.D. 2007. Soil enzyme inhibition by condensed litter tannins may drive ecosystem structure and processes: the case of Kalmia angustifolia. New Phytologist 175, 535-546.

33. Jones, S.E., Lennon, J.T. 2010. Dormancy contributes to the maintenance of 
microbial diversity. Proceedings of the National Academy of Sciences 107, 58815886.

34. Keller, J.K., Bridgham, S.D. 2007. Pathways of anaerobic carbon cycling across an ombrotrophic-minerotrophic peatland gradient. Limnology and Oceanography 96-107.

35. Kim, S.Y., Lee, S.H., Freeman, C., Fenner, N., Kang, H. 2008. Comparative analysis of soil microbial communities and their responses to the short-term drought in bog, fen, and riparian wetlands. Soil Biology and Biochemistry 40, 2874-2880.

36. Kolka, R.K., Sebestyen, S.D., Verry, E.S., Brooks, K.N. 2011. Peatland biogeochemistry and watershed hydrology at the Marcell Experimental Forest. Taylor \& Francis Group, LLC, Boca Raton.

37. Laanbroek, H.J. 2009. Methane emission from natural wetlands: interplay between emergent macrophytes and soil microbial processes. A mini-review. Annals of Botany 105, 141-153.

38. Lennon, J.T., Jones, S.E. 2011. Microbial seed banks: the ecological and evolutionary implications of dormancy. Nature Reviews Microbiology 9, 119130.

39. Lin, X., Green, S., Tfaily, M.M., Prakash, O., Konstantinidis, K.T., Corbett, J.E., Chanton, J.P., Cooper, W.T., Kostka, J.E. 2012. Microbial community structure and activity linked to contrasting biogeochemical gradients in bog and fen environments of the Glacial Lake Agassiz Peatland. Applied and Environmental Microbiology 78, 7023-7031. 
40. Lindahl, B.O., Taylor, A.F., Finlay, R.D. 2002. Defining nutritional constraints on carbon cycling in boreal forests - towards a less "phytocentric" perspective. Plant and Soil 242, 123-135.

41. Magoc, T., Salzberg, S.L. 2011. FLASH: fast length adjustment of short reads to improve genome assemblies. Bioinformatics 27, 2957-2963.

42. Myers, B., Webster, K.L., McLaughlin, J.W., Basiliko, N. 2011. Microbial activity across a boreal peatland nutrient gradient: the role of fungi and bacteria. Wetlands Ecology and Management 20, 77-88.

43. Oksanen, J., Blanchet, F.G., Kindt, R., Legendre, P., O'Hara, R.B., Simpson, G.L., Solymos, P., Stevens, M.H.H., Wagner, H. 2011. vegan: Community Ecology Package. R package version 1.17-9.

44. Olefeldt, D., Roulet, N.T. 2012. Effects of permafrost and hydrology on the composition and transport of dissolved organic carbon in a subarctic peatland complex. Journal of Geophysical Research 117, 1-15.

45. Peltoniemi, K., Fritze, H., Laiho, R. 2009. Response of fungal and actinobacterial communities to water-level drawdown in boreal peatland sites. Soil Biology and Biochemistry 41, 1902-1914.

46. Roulet, N.T., Moore, T.R., Bubier, J., Lafleur, P. 1992. Northern fens: methane flux and climatic change. Tellus B 44, 100-105.

47. Saiya-Cork, K.R., Sinsabaugh, R.L., Zak, D.R. 2002. The effects of long term nitrogen deposition on extracellular enzyme activity in an Acer saccharum forest 
soil. Soil Biology and Biochemistry 34, 1309-1315.

48. Schlesinger, W.H. 1997. Biogeochemistry: An Analysis of Global Change. $2^{\text {nd }}$ Edition. Academic Press, San Diego, California, USA.

49. Shannon, R.D., White, J.R. 1996. The effects of spatial and temporal variations in acetate and sulfate on methane cycling in two Michigan peatlands. Limnology and Oceanography 41, 435-443.

50. Sowerby, A., Emmett, B., Beier, C., Tietema, A., Peñuelas, J., Estiarte, M., Van Meeteren, M.J.M., Hughes, S., Freeman, C. 2005. Microbial community changes in heathland soil communities along a geographical gradient: interaction with climate change manipulations. Soil Biology and Biochemistry 37, 1805-1813.

51. Strack, M., Waller, M.F., Waddington, J.M. 2006. Sedge succession and peatland methane dynamics: a potential feedback to climate change. Ecosystems 9, 278-287.

52. Straková, P., Niemi, R.M., Freeman, C., Peltoniemi, K., Toberman, H., Heiskanen, I., Fritze, H., Laiho, R. 2011. Litter type affects the activity of aerobic decomposers in a boreal peatland more than site nutrient and water table regimes. Biogeosciences 8, 2741-2755.

53. Sundh, I., Nilsson, M., Granberg, G., Svensson, B.H. 1994. Depth distribution of microbial production and oxidation of methane in northern boreal peatlands. Microbial Ecology 27, 253-265.

54. Trettin, C.C., Laiho, R., Minkkinen, K., Laine, J. 2006. Influence of climate change factors on carbon dynamics in northern forested peatlands. Canadian 
Journal of Soil Science 86, 269-280.

55. Tsonis, A.A., Triantafyllou, G.N., Georgakakos, K.P. 1996. Hydrological applications of satellite data: 1. Rainfall estimation. Journal of Geophysical Research 101, 26517-26525.

56. Tveit, A., Schwacke, R., Svenning, M.M., Urich, T. 2012. Organic carbon transformations in high-Arctic peat soils: key functions and microorganisms. The ISME Journal (2012) 1-13.

57. van Elsas, J.D., Boersma, F.G.H. 2011. A review of molecular methods to study the microbiota of soil and the mycosphere. European Journal of Soil Biology 47, $77-87$.

58. Waksman, S.A., Stevens, K.R. 1929. Contribution to the chemical composition of peat. V. The role of microorganisms in peat formation and decomposition. Soil Science 28, 315-339.

59. Ward, N.L., Challacombe, J.F., Janssen, P.H., Henrissat, B., Coutinho, P.M., Wu, M., Xie, G., Haft, D.H., Sait, M., Badger, J., Barabote, R.D., Bradley, B., Brettin, T.S., Brinkac, L.M., Bruce, D., Creasy, T., Daugherty, S.C., Davidsen, T.M., DeBoy, R.T., Detter, J.C., Dodson, R.J., Durkin, A.S., Ganapathy, A., GwinnGiglio, M., Han, C.S., Khouri, H., Kiss, H., Kothari, S.P., Madupu, R., Nelson, K.E., Nelson, W.C., Paulsen, I., Penn, K., Ren, Q., Rosovitz, M.J., Selengut, J.D., Shrivastava, S., Sullivan, S.A., Tapia, R., Thompson, L.S., Watkins, K.L., Yang, Q., Yu, C., Zafar, N., Zhou, L., Kuske, C.R. 2009. Three genomes from the phylum Acidobacteria provide insight into the lifestyle of these microorganisms in soils. Applied and Environmental Microbiology 75, 2046-2056. 
60. Whalen, S.C. 2005. Biogeochemistry of methane exchange between natural wetlands and the atmosphere. Environmental Engineering Science 22, 73-94.

61. Weishaar, J.L., Aiken, G.R., Bergamaschi, B.A., Fram, M.S., Fujii, R., Mopper, K. 2003. Evaluation of specific ultraviolet absorbance as an indicator of the chemical composition and reactivity of dissolved organic carbon. Environmental Science \& Technology 37, 4702-4708.

62. Weltzin, J.F., Pastor, J., Harth, C., Bridgham, S.D., Updegraff, K., Chapin, C.T. 2000. Response of bog and fen plant communities to warming and water-table manipulations. Ecology 81, 3464-3478. 


\subsection{Tables}

Table 1 Oxidative and hydrolytic extracellular enzymes assayed in bulk peat at the $10-20 \mathrm{~cm}$ depth with corresponding enzyme commission number (EC), role in nutrient cycling, and substrate.

\begin{tabular}{llllll}
\hline Enzyme & Abbreviation & EC & Type & Nutrient Cycle & Substrate \\
\hline Phenol oxidase & POX & 1.10 .3 .2 & Oxidative & Carbon & L-DOPA \\
Peroxidase & PER & 1.11 .1 .7 & Oxidative & Carbon & L-DOPA \\
Sulfatase & SULF & 3.1 .6 .1 & Hydrolytic & Sulfur & 4-MUB-sulfate potassium salt \\
$\beta-1,4-$ glucosidase & GLUC & 3.2 .1 .21 & Hydrolytic & Carbon & 4-MUB- $\beta$-D-glucopyranoside \\
Acid-phosphatase & PHOS & 3.1 .3 .2 & Hydrolytic & Phosphorus & 4-MUB-phosphate \\
\hline L-DOPA = L-3,4-dihydroxyphenylalanine; 4-MUB $=$ 4-methylumbelliferyl & &
\end{tabular}


Table 2 Bacterial and archaeal diversity indicated by Chao1 richness and equitability evenness in plant functional group treatments.

\begin{tabular}{|c|c|c|c|c|c|c|c|}
\hline \multirow[b]{3}{*}{ Treatment } & \multirow[b]{3}{*}{ Depth $(\mathrm{cm})$} & \multicolumn{3}{|l|}{ Bacteria } & \multicolumn{3}{|c|}{ Archaea } \\
\hline & & \multicolumn{3}{|l|}{ Sequence } & \multicolumn{3}{|c|}{ Sequence } \\
\hline & & Read & Chao1 & Equitability & Read & Chaol & Equitability \\
\hline Sedge & $10-20$ & 197,708 & $2,082 \pm 363$ & $0.78 \pm 0.03$ & 965 & $10 \pm 5$ & $0.79 \pm 0.08$ \\
\hline Sedge & $30-40$ & 291,657 & $1,968 \pm 174$ & $0.74 \pm 0.02$ & 2,471 & $11 \pm 3$ & $0.80 \pm 0.15$ \\
\hline Unmanipulated & $10-20$ & 276,899 & $2,123 \pm 197$ & $0.77 \pm 0.03$ & 976 & $8 \pm 4$ & $0.74 \pm 0.11$ \\
\hline Unmanipulated & $30-40$ & 224,881 & $1,948 \pm 218$ & $0.75 \pm 0.04$ & 2,309 & $12 \pm 3$ & $0.80 \pm 0.12$ \\
\hline Ericaceae & $10-20$ & 253,350 & $2,038 \pm 265$ & $0.75 \pm 0.03$ & 804 & $13 \pm 11$ & $0.73 \pm 0.17$ \\
\hline Ericaceae & $30-40$ & 290,087 & $1,920 \pm 262$ & $0.75 \pm 0.04$ & 2,188 & $11 \pm 5$ & $0.84 \pm 0.16$ \\
\hline
\end{tabular}

Calculations based on OTU tables rarefied to the smallest total sequencing read per sample to minimize the effects of variable sampling effort in comparing diversity across samples. Sequence reads are the sum of sequences generated per treatment combination. Diversity values are arranged by treatment combination with numbers following " \pm " indicating standard deviation. 
Table 3 Mean ( \pm SE) percent relative abundance of bacterial phyla and archaeal orders between plant functional groups within sampling depths.

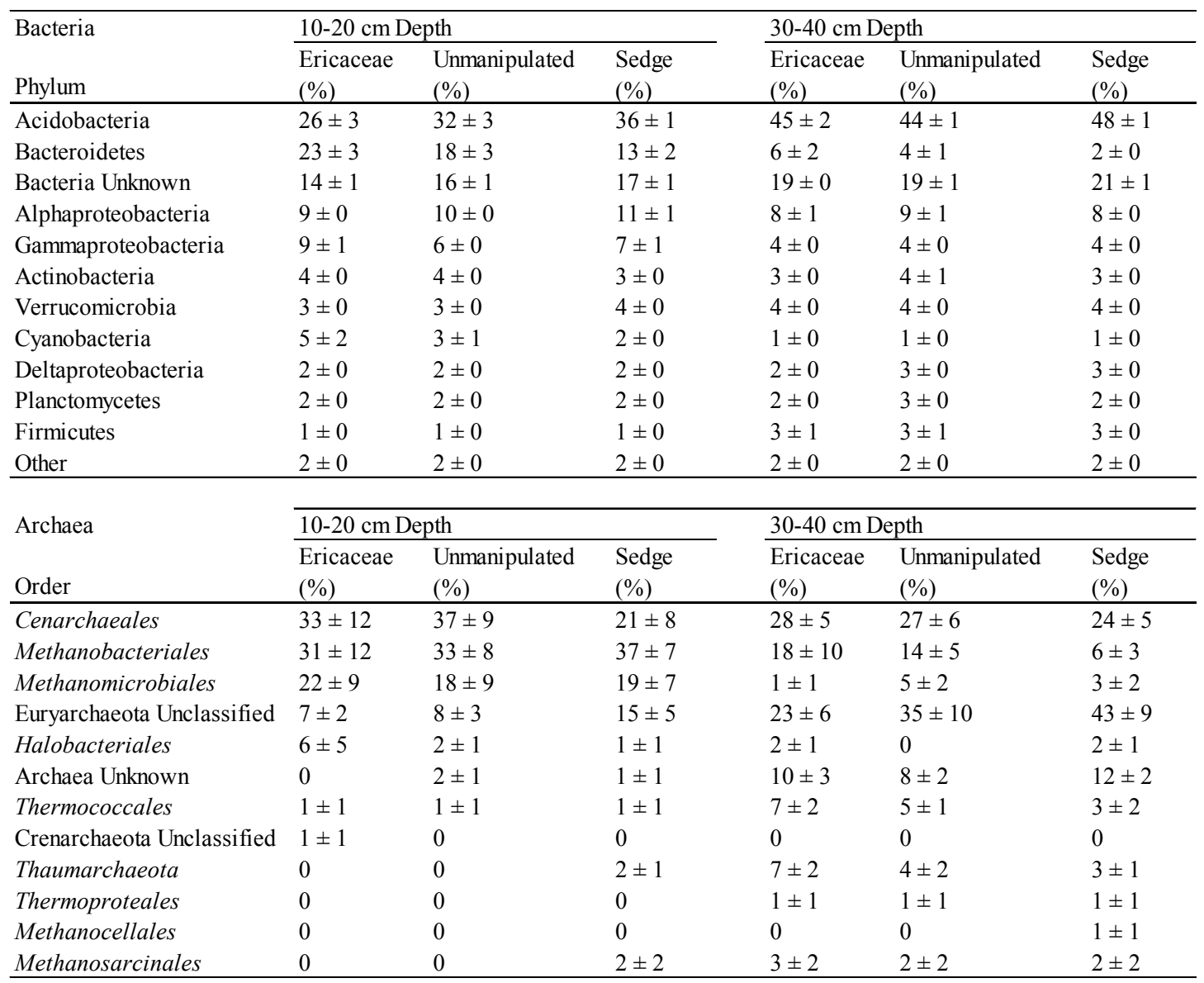

Numbers following " \pm " indicate standard error. "Other" contains the seven relatively rare remaining phyla and three

Proteobacteria classes that combined represent less than $5 \%$ of total community composition. 
Table 4 Peat soil biogeochemistry, relative percentage of vegetation, and extracellular enzyme activities by plant functional group treatments within depths.

\begin{tabular}{|c|c|c|c|c|c|c|}
\hline Treatment & Depth $(\mathrm{cm})$ & $\mathrm{pH}$ & $\begin{array}{l}\mathrm{DOC} \\
\left(\mathrm{mg} \mathrm{L}^{-1}\right)\end{array}$ & $\begin{array}{l}\mathrm{TDN} \\
\left(\mathrm{mg} \mathrm{L}^{-1}\right)\end{array}$ & $\mathrm{E}_{2}: \mathrm{E}_{3}$ & $\mathrm{SUVA}_{254}$ \\
\hline Sedge & $10-20$ & $3.96 \pm 0.18$ & $92.6 \pm 19.8$ & $2.9 \pm 1.0$ & $7.0 \pm 0.7$ & $4.5 \pm 0.2$ \\
\hline Sedge & $30-40$ & $3.84 \pm 0.11$ & $99.7 \pm 23.0$ & $2.9 \pm 1.0$ & $6.4 \pm 0.7$ & $4.3 \pm 0.2$ \\
\hline Unmanipulated & $10-20$ & $3.82 \pm 0.20$ & $111.6 \pm 21.4$ & $2.9 \pm 0.6$ & $6.5 \pm 0.8$ & $4.2 \pm 0.2$ \\
\hline Unmanipulated & $30-40$ & $3.83 \pm 0.13$ & $117.5 \pm 22.7$ & $3.1 \pm 0.7$ & $5.9 \pm 0.7$ & $4.0 \pm 0.2$ \\
\hline Ericaceae & $10-20$ & $3.86 \pm 0.11$ & $111.3 \pm 25.0$ & $2.9 \pm 0.7$ & $6.8 \pm 0.8$ & $4.0 \pm 0.2$ \\
\hline \multirow[t]{3}{*}{ Ericaceae } & $30-40$ & $3.77 \pm 0.08$ & $121.5 \pm 23.5$ & $3.3 \pm 0.8$ & $5.9 \pm 0.7$ & $3.8 \pm 0.2$ \\
\hline & & \multicolumn{5}{|c|}{ Relative Percentage (\%) } \\
\hline & $\begin{array}{l}\text { Water Table } \\
(\mathrm{cm})\end{array}$ & $\begin{array}{l}\text { Carex } \\
\text { oligosperma }\end{array}$ & $\begin{array}{l}\text { Andromeda } \\
\text { glaucophylla }\end{array}$ & $\begin{array}{l}\text { Chamaedaphne } \\
\text { calyculata }\end{array}$ & $\begin{array}{l}\text { Kalmia } \\
\text { polifolia }\end{array}$ & $\begin{array}{l}\text { Vaccinium } \\
\text { oxycoccos }\end{array}$ \\
\hline Sedge & $-7.4 \pm 3.2$ & $29 \pm 1$ & $0 \pm 1$ & $1 \pm 8$ & $0 \pm 11$ & $6 \pm 11$ \\
\hline Unmanipulated & $-7.4 \pm 2.4$ & $14 \pm 15$ & $0 \pm 0$ & $20 \pm 1$ & $18 \pm 1$ & $34 \pm 5$ \\
\hline \multirow[t]{2}{*}{ Ericaceae } & $-7.2 \pm 2.5$ & $0 \pm 10$ & $0 \pm 0$ & $23 \pm 9$ & $21 \pm 4$ & $42 \pm 8$ \\
\hline & & \multicolumn{5}{|c|}{ Extracellular Enzyme Activity } \\
\hline Treatment & Depth $(\mathrm{cm})$ & $\begin{array}{l}\text { Phenol Oxidase } \\
\left(\mu \mathrm{mol} \mathrm{h} \mathrm{g}^{-1}\right)\end{array}$ & $\begin{array}{l}\text { Peroxidase } \\
\left(\mu \mathrm{mol} \mathrm{h} \mathrm{h}^{-1} \mathrm{~g}^{-1}\right) \\
\end{array}$ & $\begin{array}{l}\beta \text {-Glucosidase } \\
\left(\mathrm{nmol} \mathrm{hr}{ }^{-1} \mathrm{~g}^{-1}\right)\end{array}$ & $\begin{array}{l}\text { Sulfatase } \\
\left(\mathrm{nmol} \mathrm{hr} \mathrm{g}^{-1}\right)\end{array}$ & $\begin{array}{l}\text { Acid-Phosphatase } \\
\left(\mathrm{nmol} \mathrm{hr} \mathrm{g}^{-1}\right)\end{array}$ \\
\hline Sedge & $10-20$ & $1.42 \pm 1.93$ & $6.90 \pm 4.47$ & $2630.6 \pm 866.2$ & $35.4 \pm 36.1$ & $6588.8 \pm 1425.6$ \\
\hline Ericaceae & $10-20$ & $0.92 \pm 2.21$ & $8.45 \pm 5.65$ & $3059.8 \pm 948.9$ & $11.2 \pm 9.0$ & $5194.6 \pm 2237.1$ \\
\hline Unmanipulated & $10-20$ & $0.62 \pm 1.01$ & $6.80 \pm 5.16$ & $2970.7 \pm 1037.6$ & $13.5 \pm 13.3$ & $6241.6 \pm 2383.9$ \\
\hline
\end{tabular}

Numbers following " \pm " indicate standard deviation 
Table 5 Statistical results for envfit function utilizing environmental data for bacteria and archaea at both $10-20 \mathrm{~cm}$ and $30-40 \mathrm{~cm}$ depths.

\begin{tabular}{|c|c|c|c|c|c|c|c|c|}
\hline & \multicolumn{4}{|c|}{ Bacteria } & \multicolumn{4}{|c|}{ Archaea } \\
\hline & \multicolumn{2}{|c|}{$10-20 \mathrm{~cm}$} & \multicolumn{2}{|c|}{$30-40 \mathrm{~cm}$} & \multicolumn{2}{|c|}{$10-20 \mathrm{~cm}$} & \multicolumn{2}{|c|}{$30-40 \mathrm{~cm}$} \\
\hline & $\mathbf{r}^{2}$ & p-value & $\mathbf{r}^{2}$ & p-value & $\mathbf{r}^{2}$ & p-value & $\mathbf{r}^{2}$ & p-value \\
\hline $\mathrm{pH}$ & 0.02 & 0.858 & 0.02 & 0.843 & 0.15 & 0.204 & 0.02 & 0.829 \\
\hline Water Table & 0.07 & 0.492 & 0.02 & 0.790 & 0.24 & 0.082 & 0.01 & 0.883 \\
\hline Carex \% & 0.52 & $0.001^{*}$ & 0.19 & 0.117 & 0.02 & 0.872 & 0.13 & 0.254 \\
\hline Chamae \% & 0.14 & 0.233 & 0.07 & 0.486 & 0.01 & 0.920 & 0.06 & 0.567 \\
\hline Kalmia \% & 0.12 & 0.301 & 0.14 & 0.218 & 0.03 & 0.782 & 0.06 & 0.546 \\
\hline Vaccin $\%$ & 0.25 & 0.085 & 0.16 & 0.169 & 0.00 & 0.965 & 0.16 & 0.199 \\
\hline DOC & 0.26 & $0.040 *$ & 0.07 & 0.505 & 0.11 & 0.333 & 0.09 & 0.388 \\
\hline TDN & 0.07 & 0.491 & 0.06 & 0.543 & 0.10 & 0.401 & 0.10 & 0.318 \\
\hline $\mathrm{E}_{2}: \mathrm{E}_{3}$ & 0.27 & $0.034 *$ & 0.16 & 0.178 & 0.15 & 0.214 & 0.16 & 0.166 \\
\hline SUVA $_{254}$ & 0.21 & 0.099 & 0.05 & 0.621 & 0.17 & 0.147 & 0.08 & 0.392 \\
\hline Phenol Oxidase & 0.04 & 0.735 & - & - & 0.06 & 0.561 & - & - \\
\hline Peroxidase & 0.20 & 0.135 & - & - & 0.41 & $0.011^{*}$ & - & - \\
\hline Sulfatase & 0.61 & $0.002 *$ & - & - & 0.32 & $0.026^{*}$ & - & - \\
\hline$\beta$-Glucosidase & 0.26 & 0.058 & - & - & 0.35 & $0.018^{*}$ & - & - \\
\hline Acid-Phosphatase & 0.03 & 0.782 & - & - & 0.00 & 0.969 & - & - \\
\hline
\end{tabular}

*p-value $<0.05$ 


\subsection{Figures}
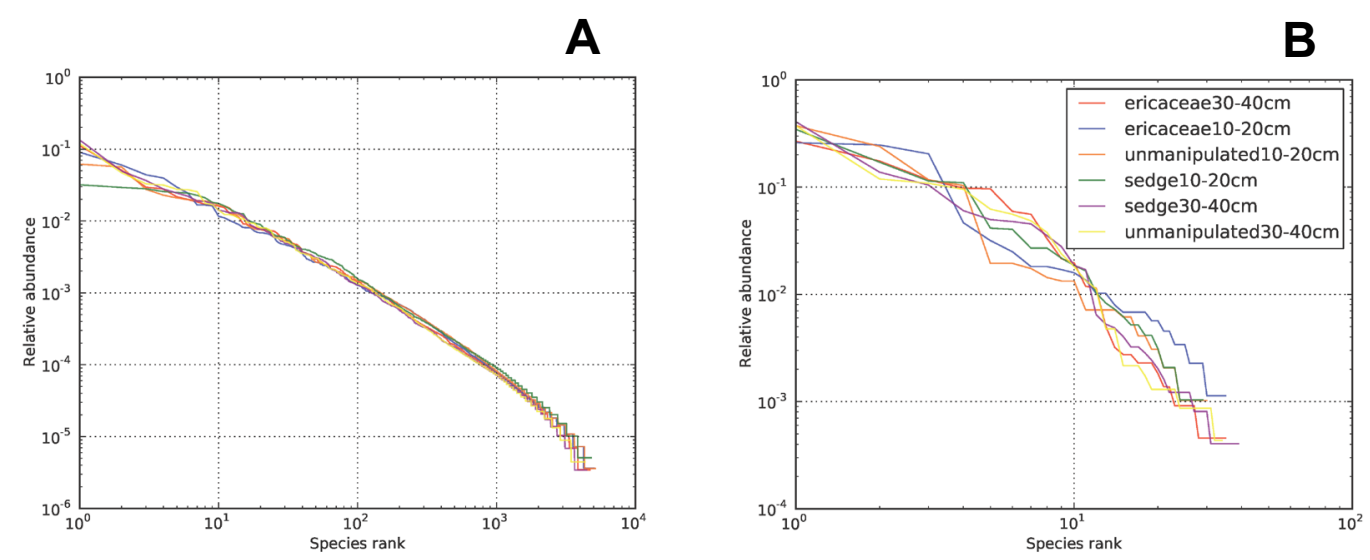

Figure 1 Rank abundance curves for relative abundance of A) bacterial and B) archaeal OTUs obtained from Illumina sequencing. Graph axes are displayed in log$\log$ scale for clarity. 


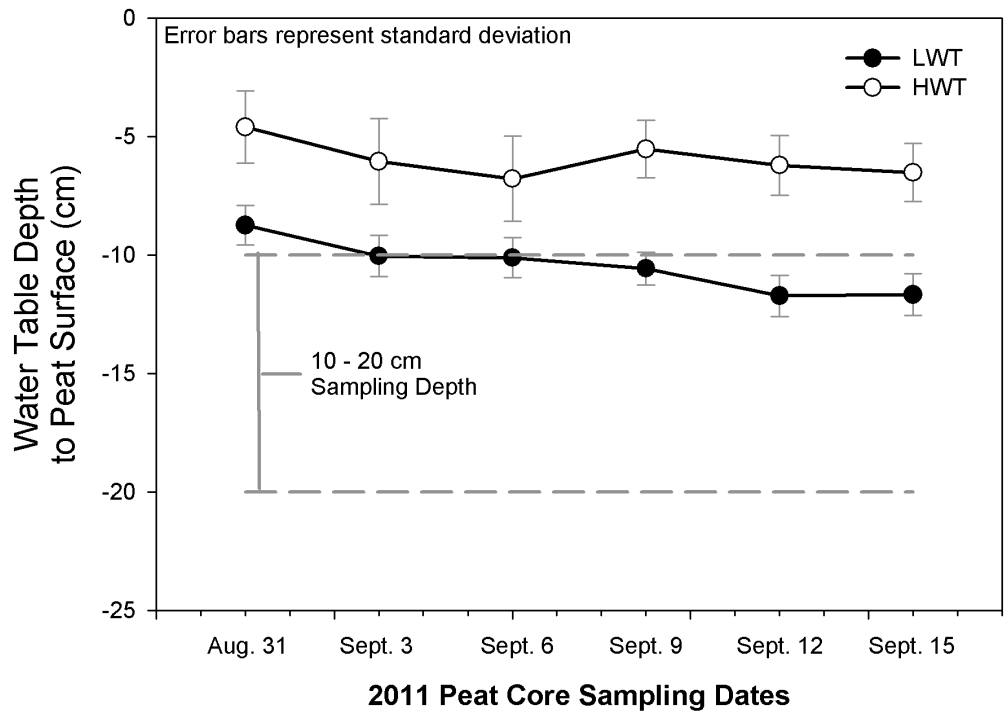

Figure 2 Water table depth in mesocosm bins for high water table treatment (HWT) and low water table treatment (LWT) during the two-week peat coring period. 


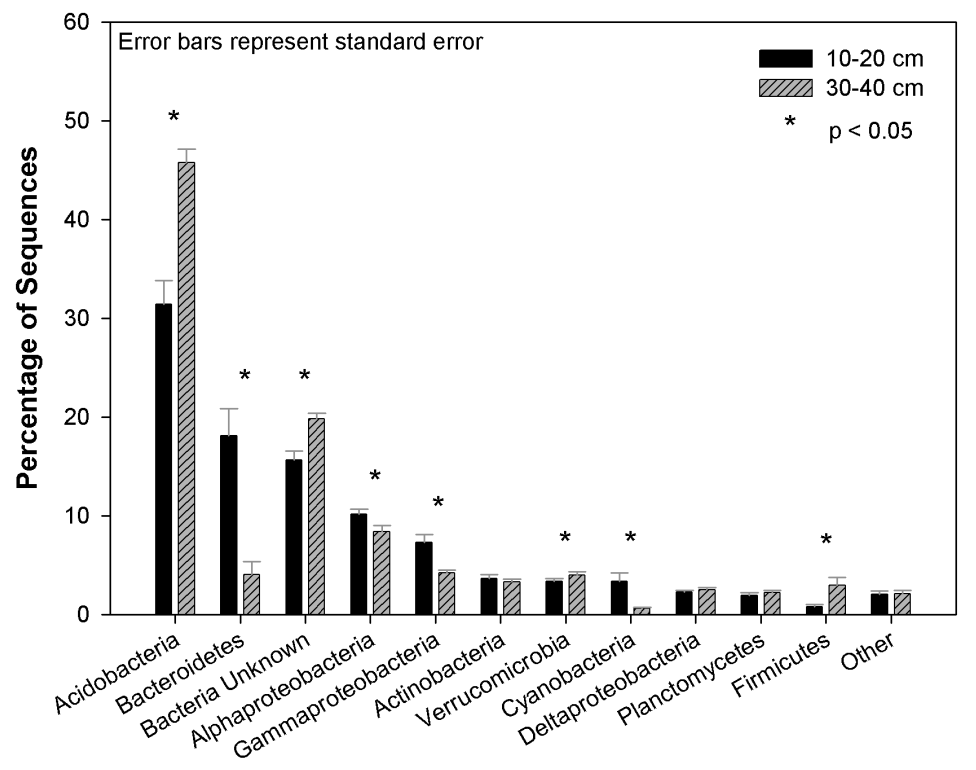

Figure 3 Bacteria phylum-level community composition between sampling depth. "Other" contains seven relatively rare remaining phyla and three Proteobacteria classes that represent less than $5 \%$ of total community composition. 

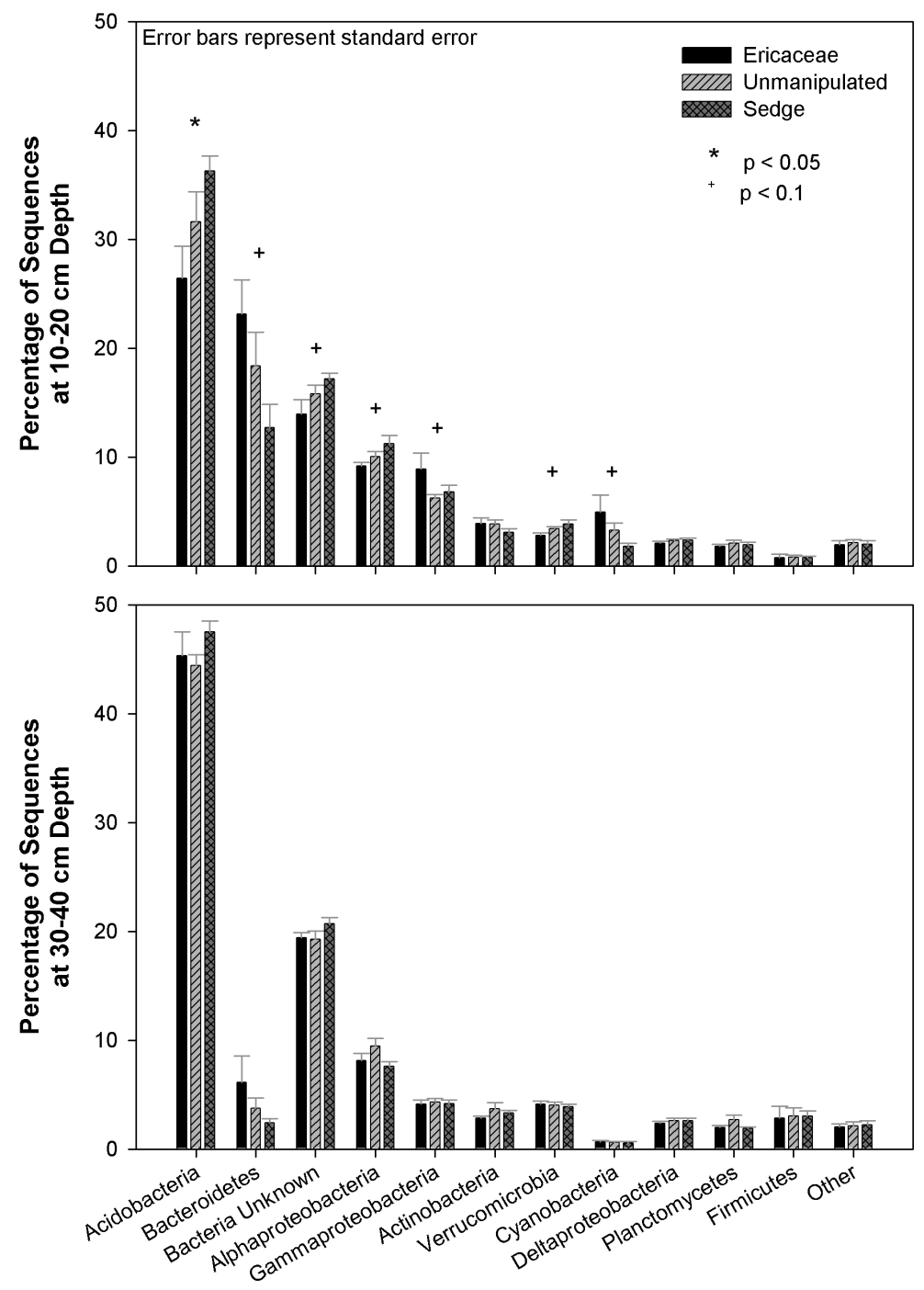

Figure 4 Bacteria phylum-level community composition between plant functional group treatments within sampling depths. "Other" contains seven relatively rare remaining phyla and three Proteobacteria classes that represent less than 5\% of total community composition 


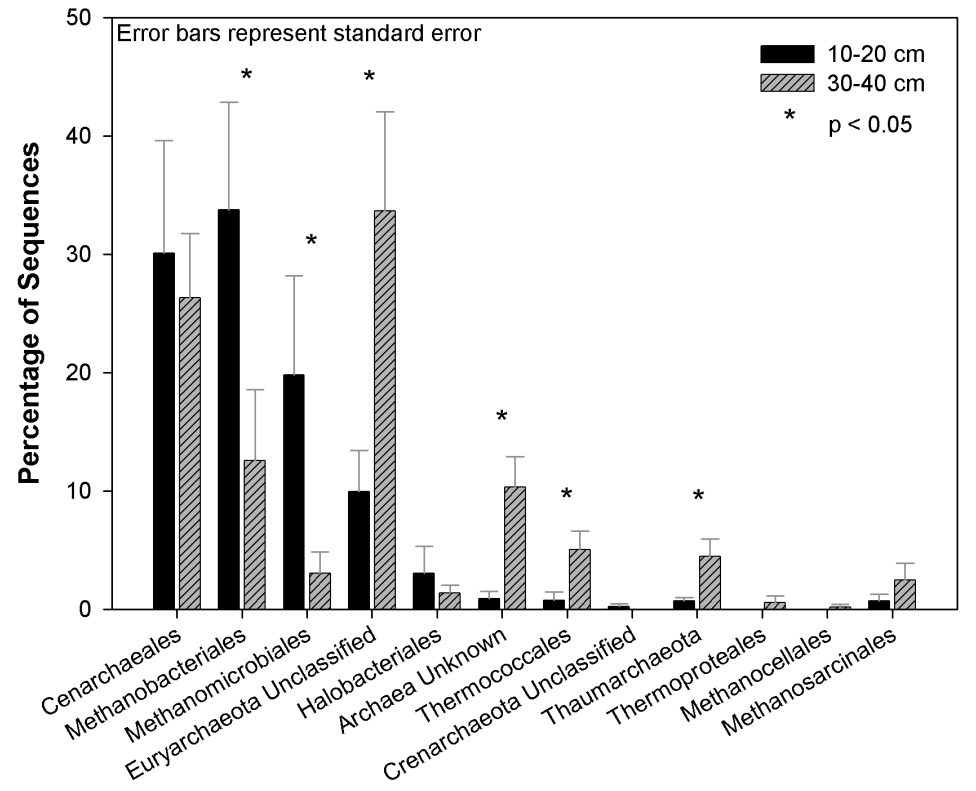

Figure 5 Archaea order-level community composition between sampling depth. 

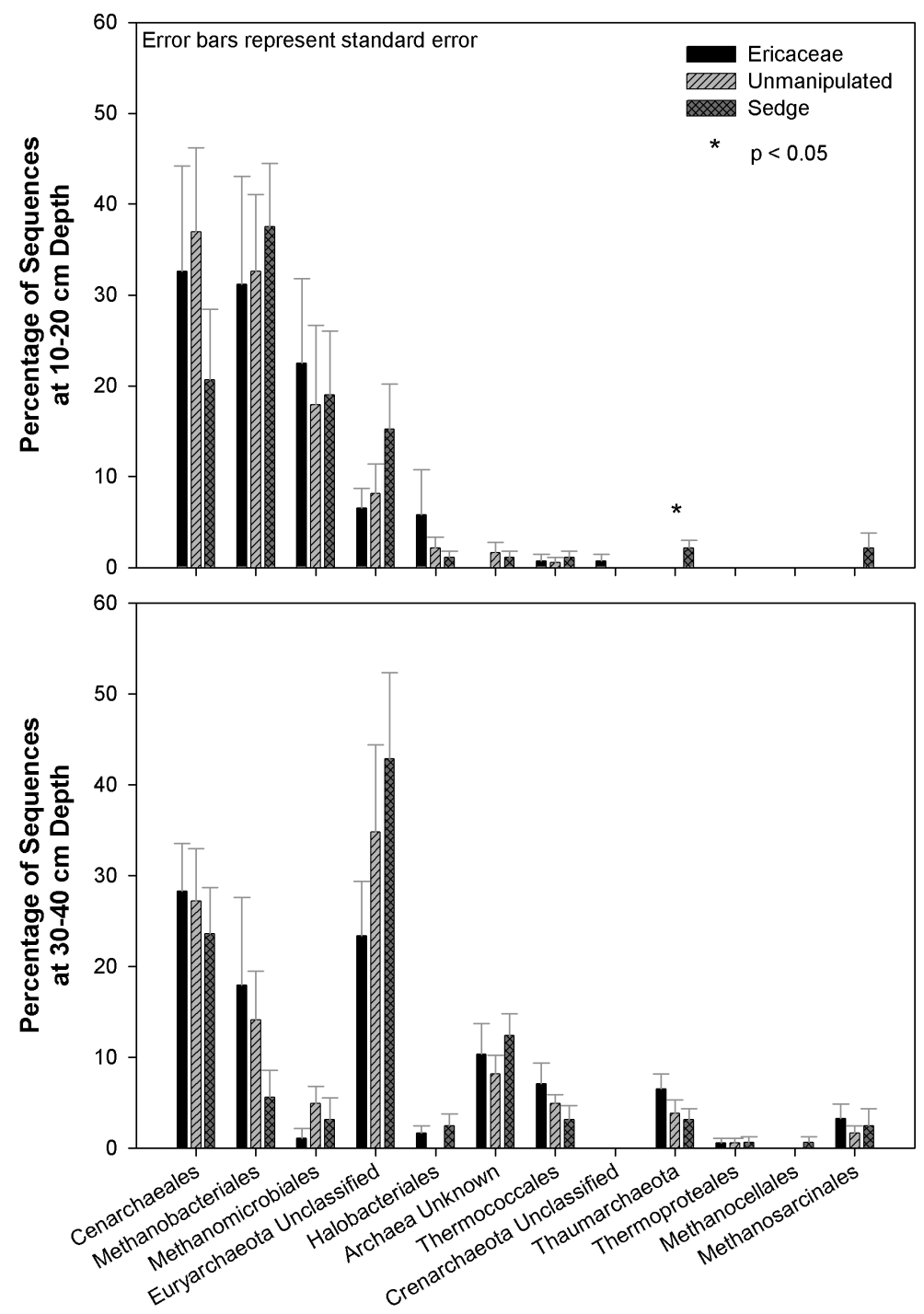

Figure 6 Archaea order-level community composition between plant functional group treatments within sampling depths. 


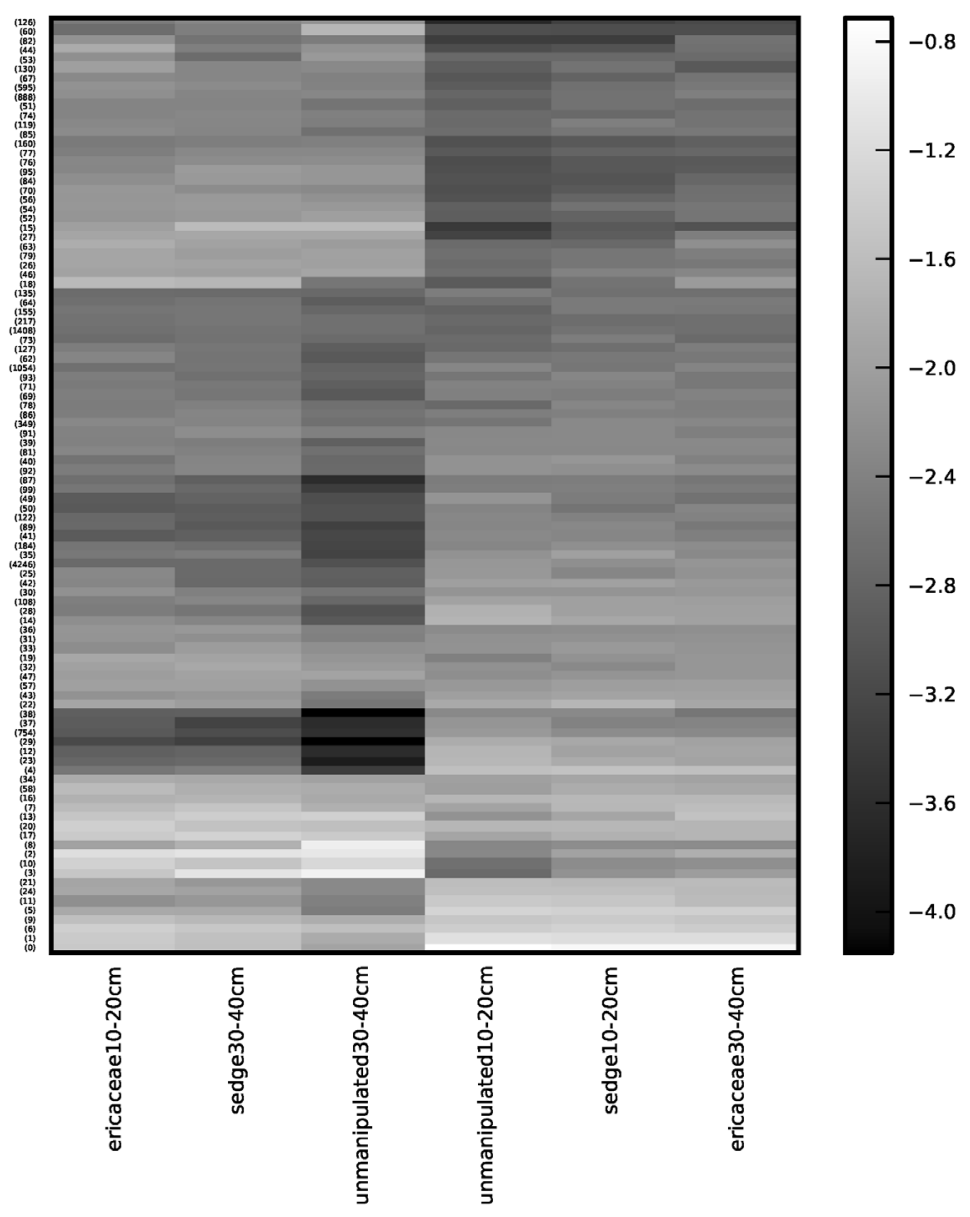

Figure 7 Heatmap visualization for top 100 most abundant bacterial OTUs indicating relative abundance by depth. Refer to Supplemental Table S1 for taxonomic identification of relevant OTUs. 


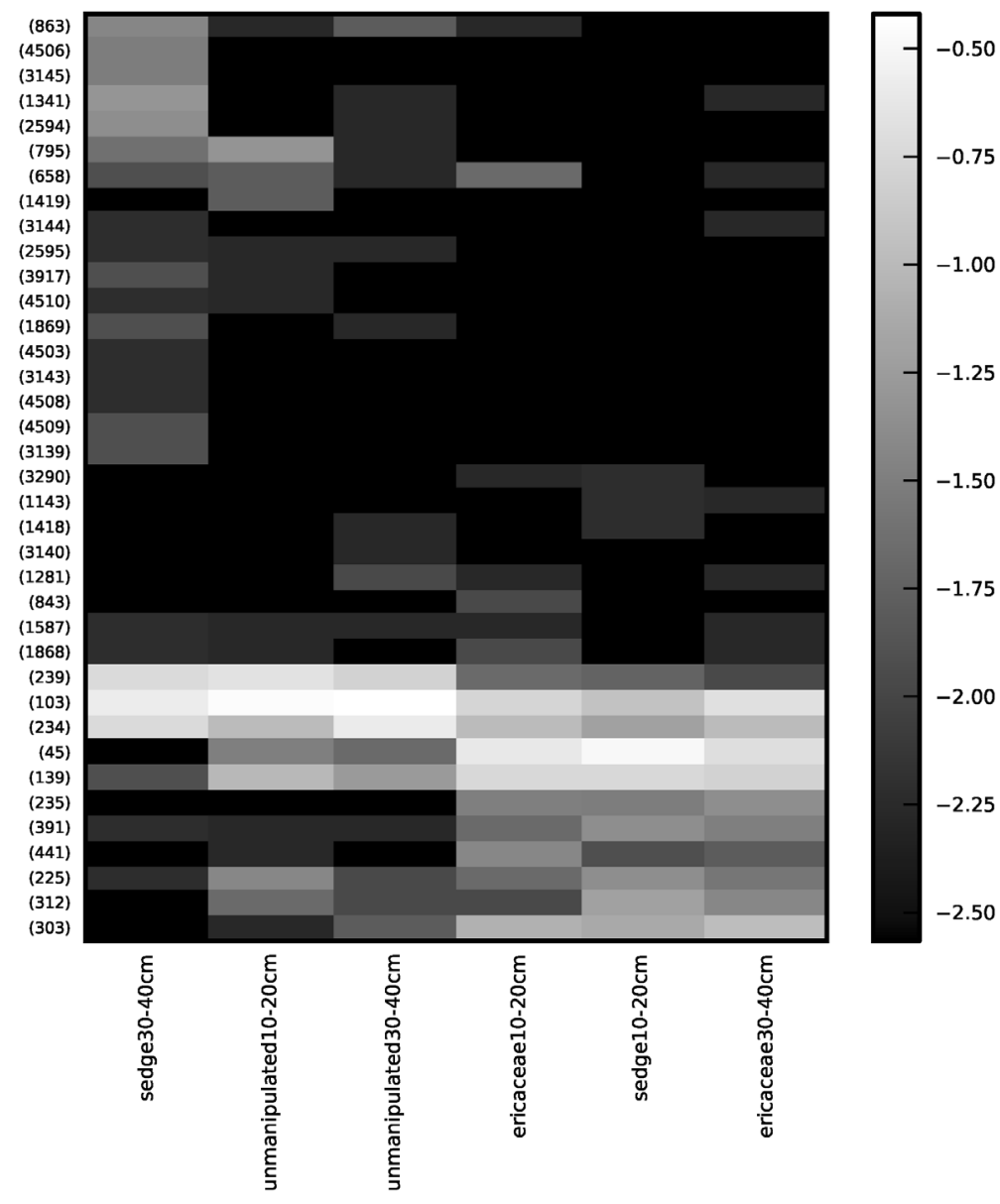

Figure 8 Heatmap visualization for all archaeal OTUs indicating relative abundance by depth. Refer to Supplemental Table S3 for taxonomic identification of relevant OTUs. 

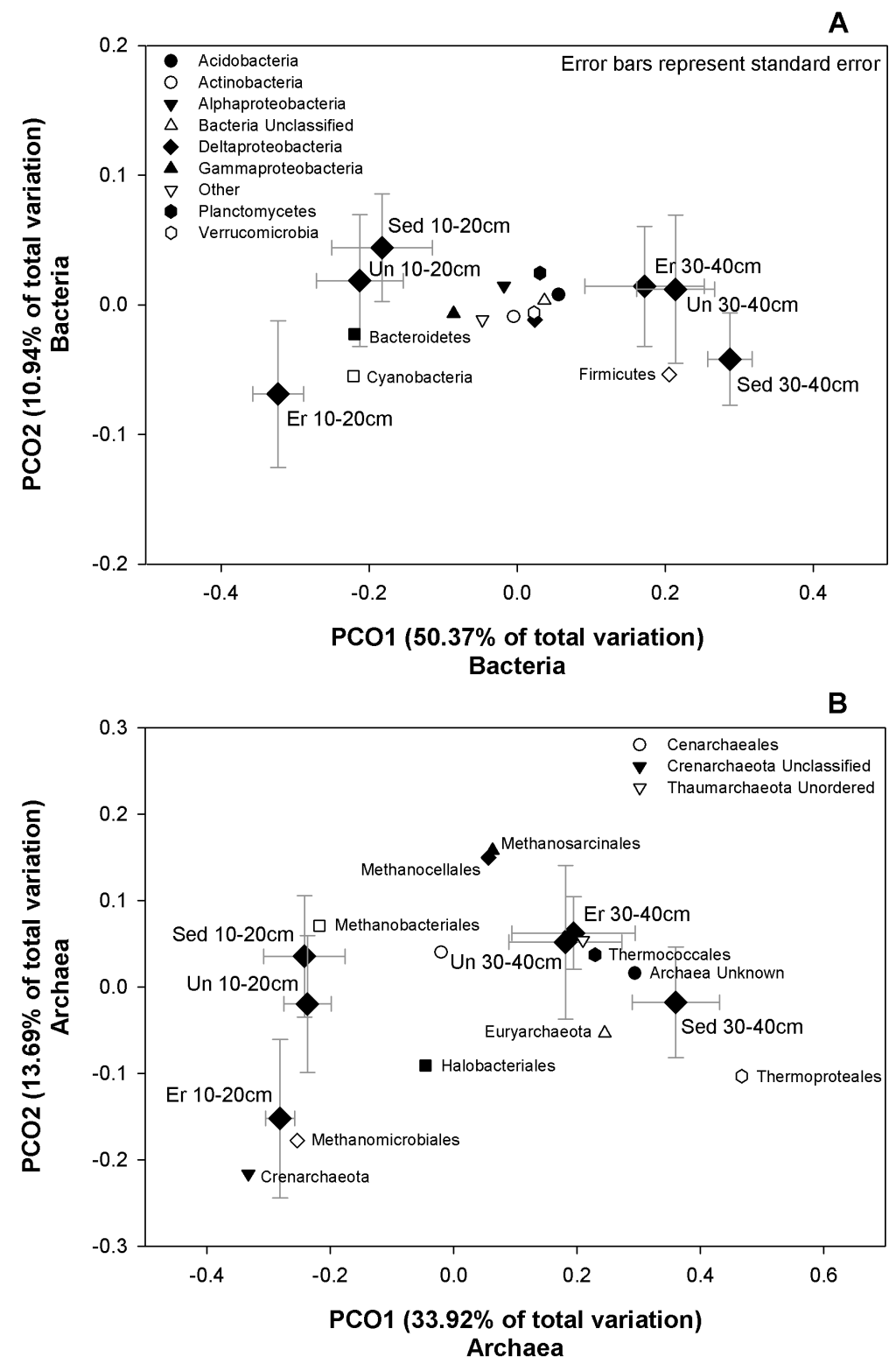

Figure 9 Principal coordinates analysis of A) bacteria and B) archaea. X-axis indicates percent of total variation explained by soil depth while Y-axis explains percent of variation explained by plant functional group treatments. 

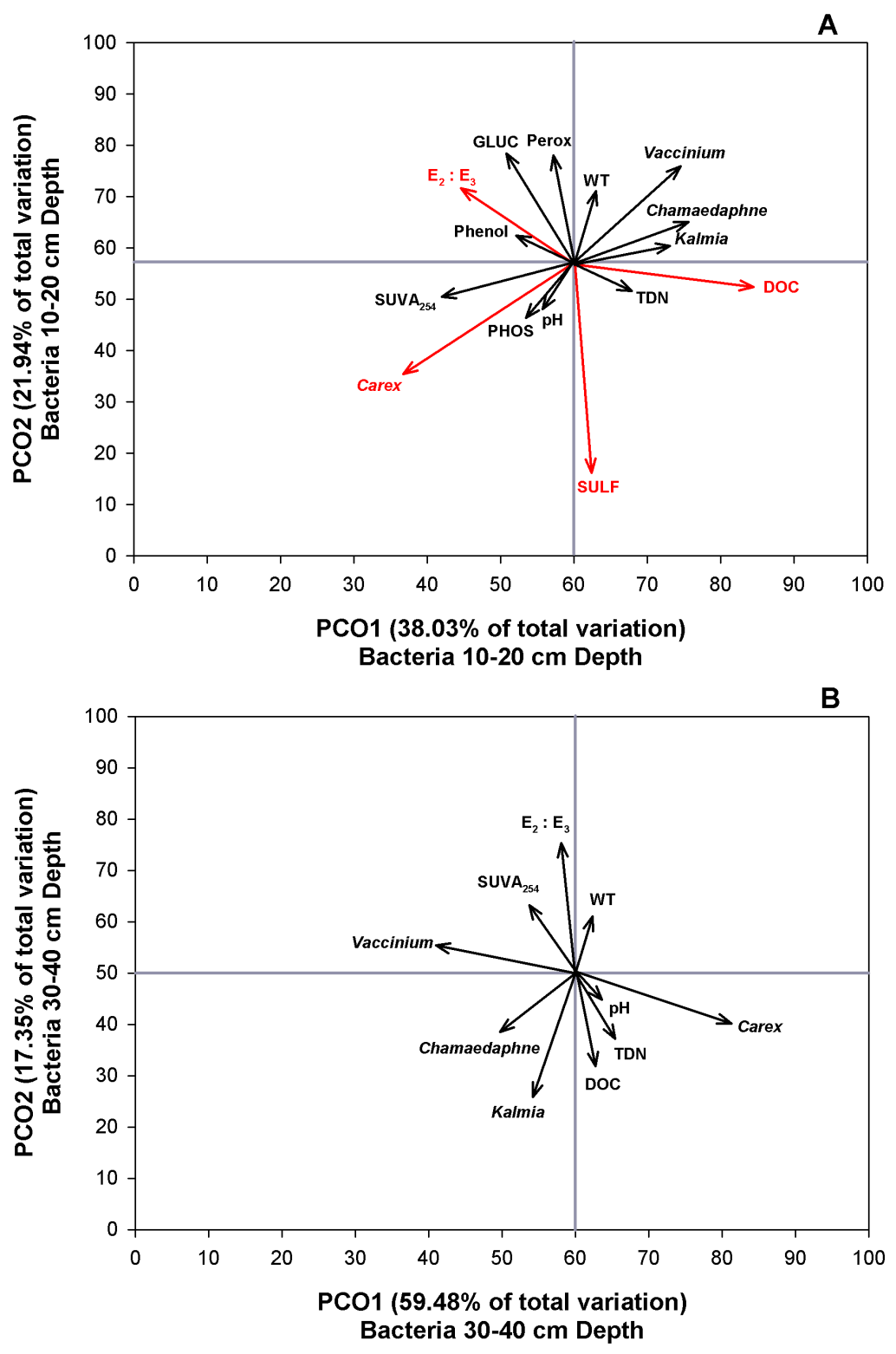

Figure 10 PCoA of top 100 OTUs with envfit environmental vectors for A) bacteria at $10-20 \mathrm{~cm}$ depth and B) bacteria at $30-40 \mathrm{~cm}$ depth. Environmental vectors that had a significant $(\mathrm{p}<0.05)$ influence on microbial community composition within the ordination are plotted in red. 

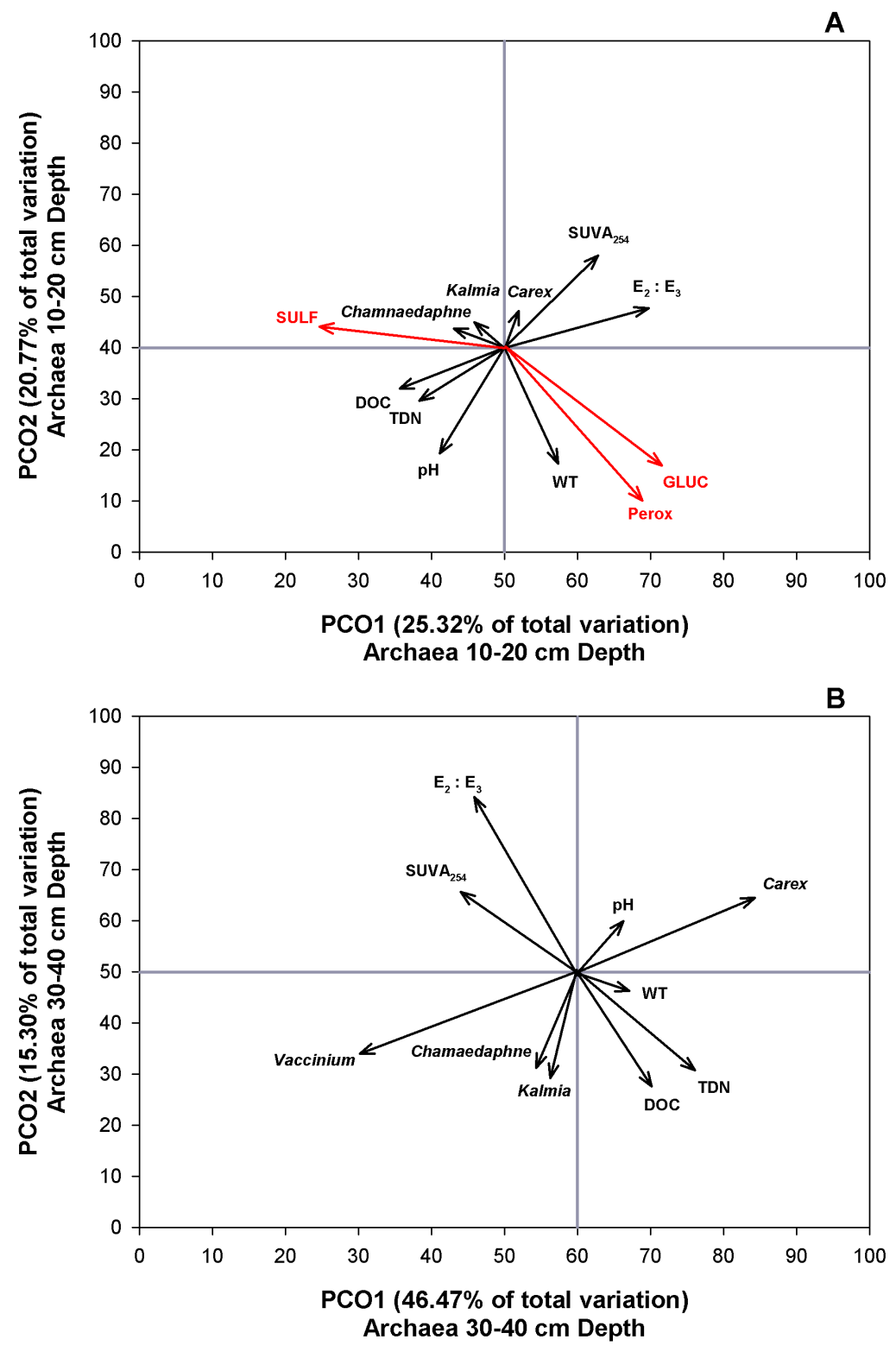

Figure 11 PCoA of all OTUs with envfit environmental vectors for A) archaea at 10$20 \mathrm{~cm}$ depth and B) archaea at 30-40 cm depth. Environmental vectors that had a significant $(p<0.05)$ influence on microbial community composition within the ordination are plotted in red. 


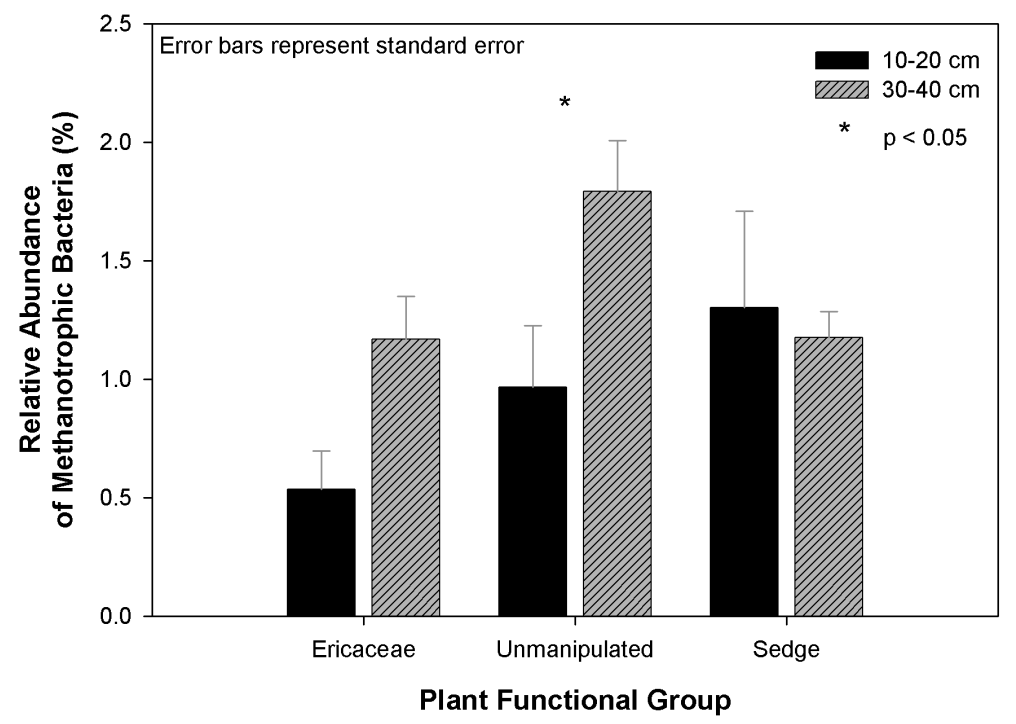

Figure 12 Mean relative abundance of all methanotrophic bacteria summed between sampling depths. Error bars represent standard error. 


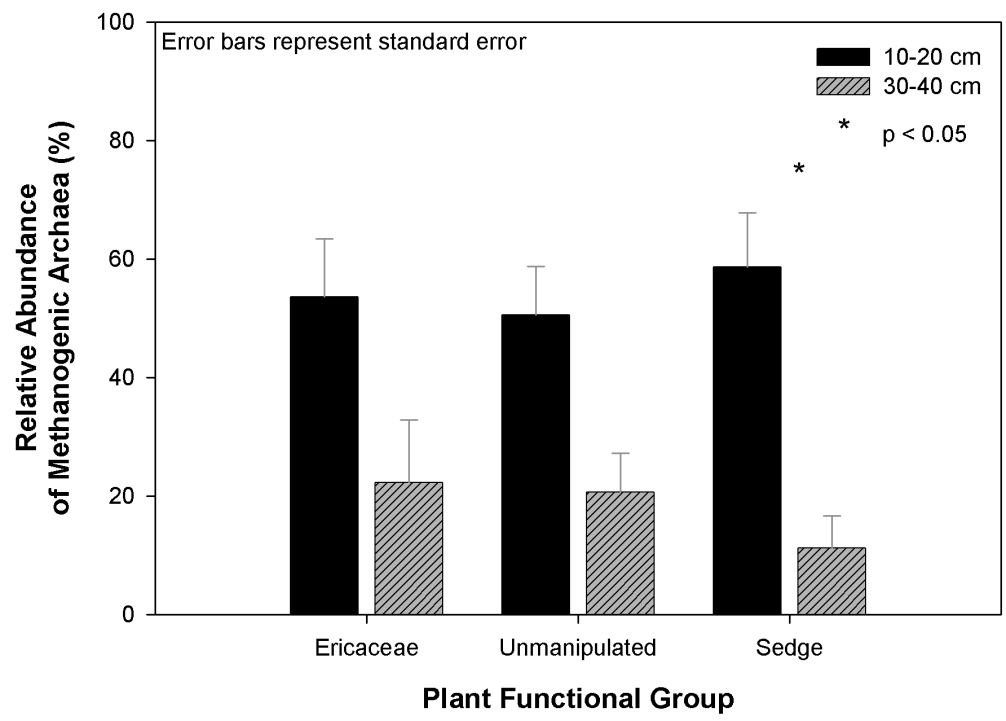

Figure 13 Mean relative abundance of all methanogenic archaea summed between sampling depths. Error bars represent standard error. 


\subsection{Supplemental}

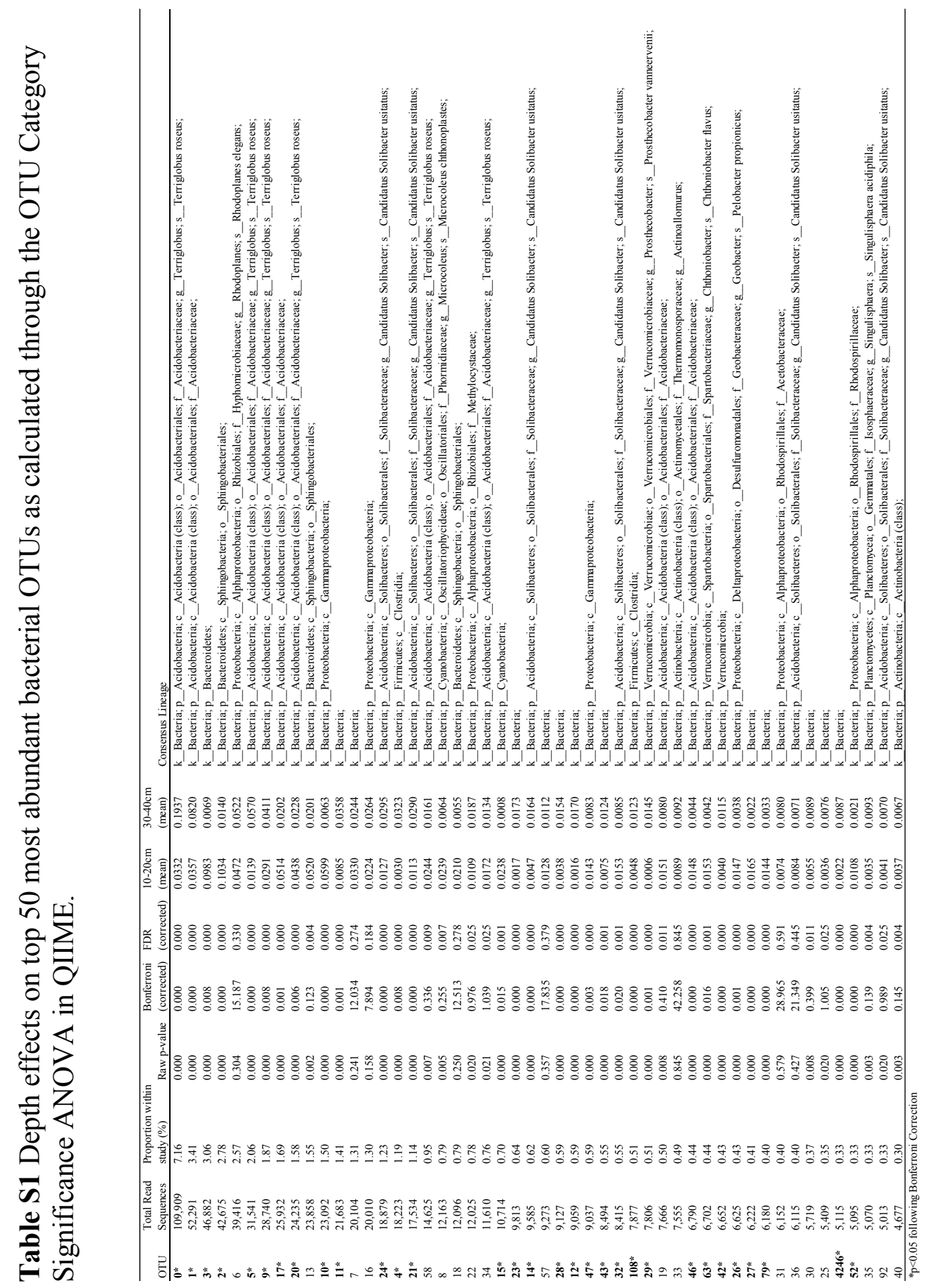




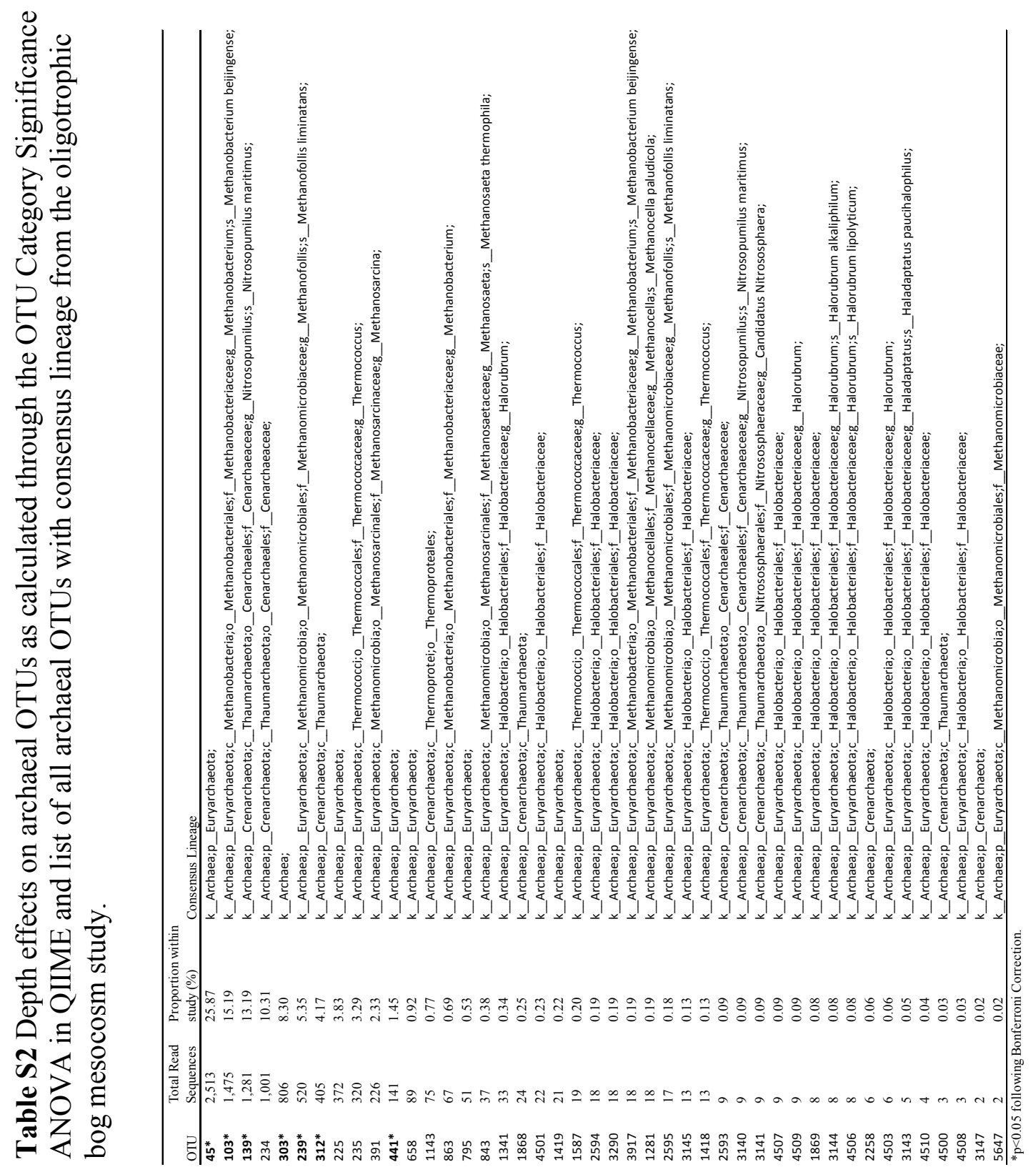




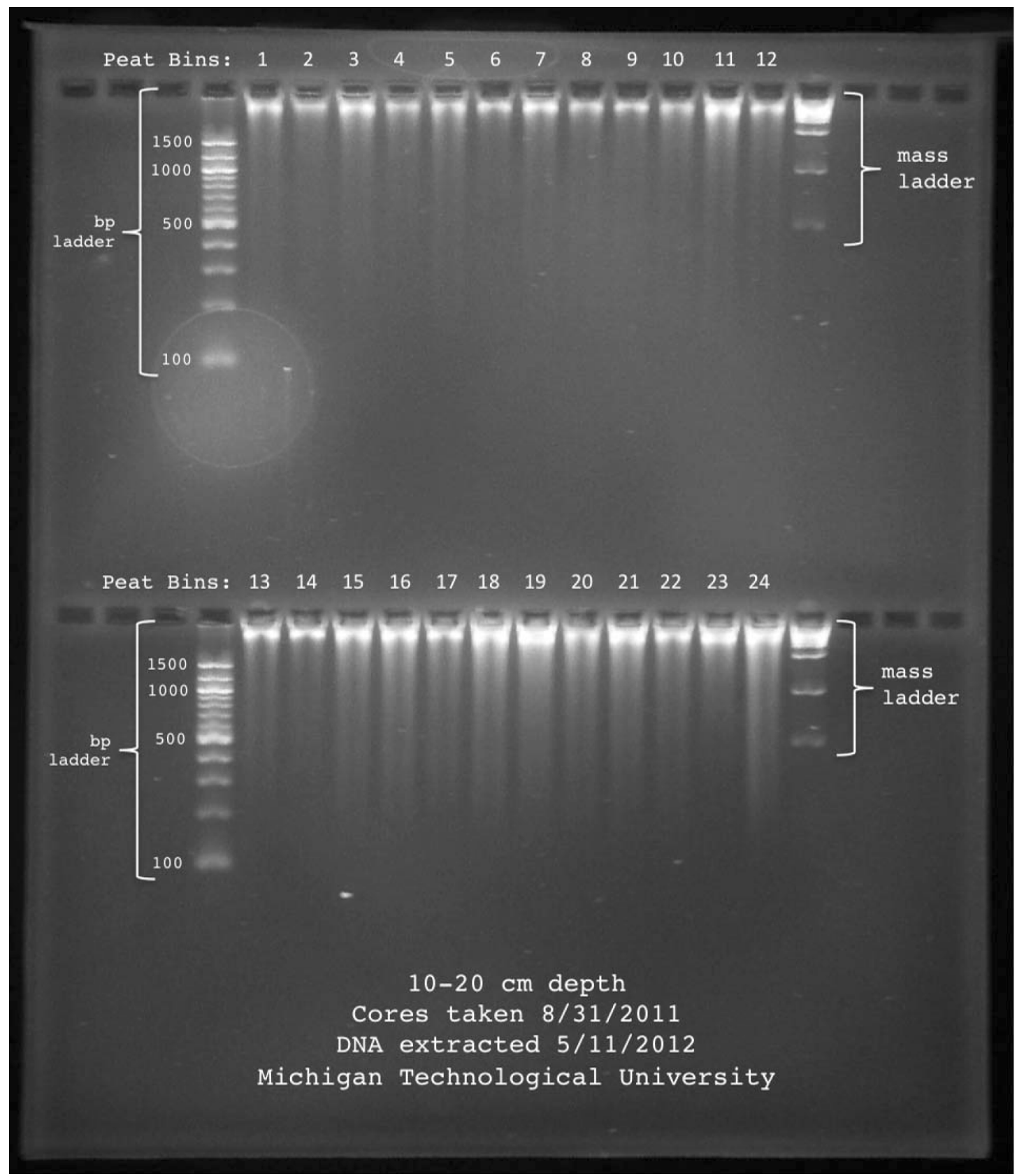

Figure S1 Electrophoresis DNA quantity visualization on 2:1\% agarose gel for DNA extractions at the 10-20 cm depth. 


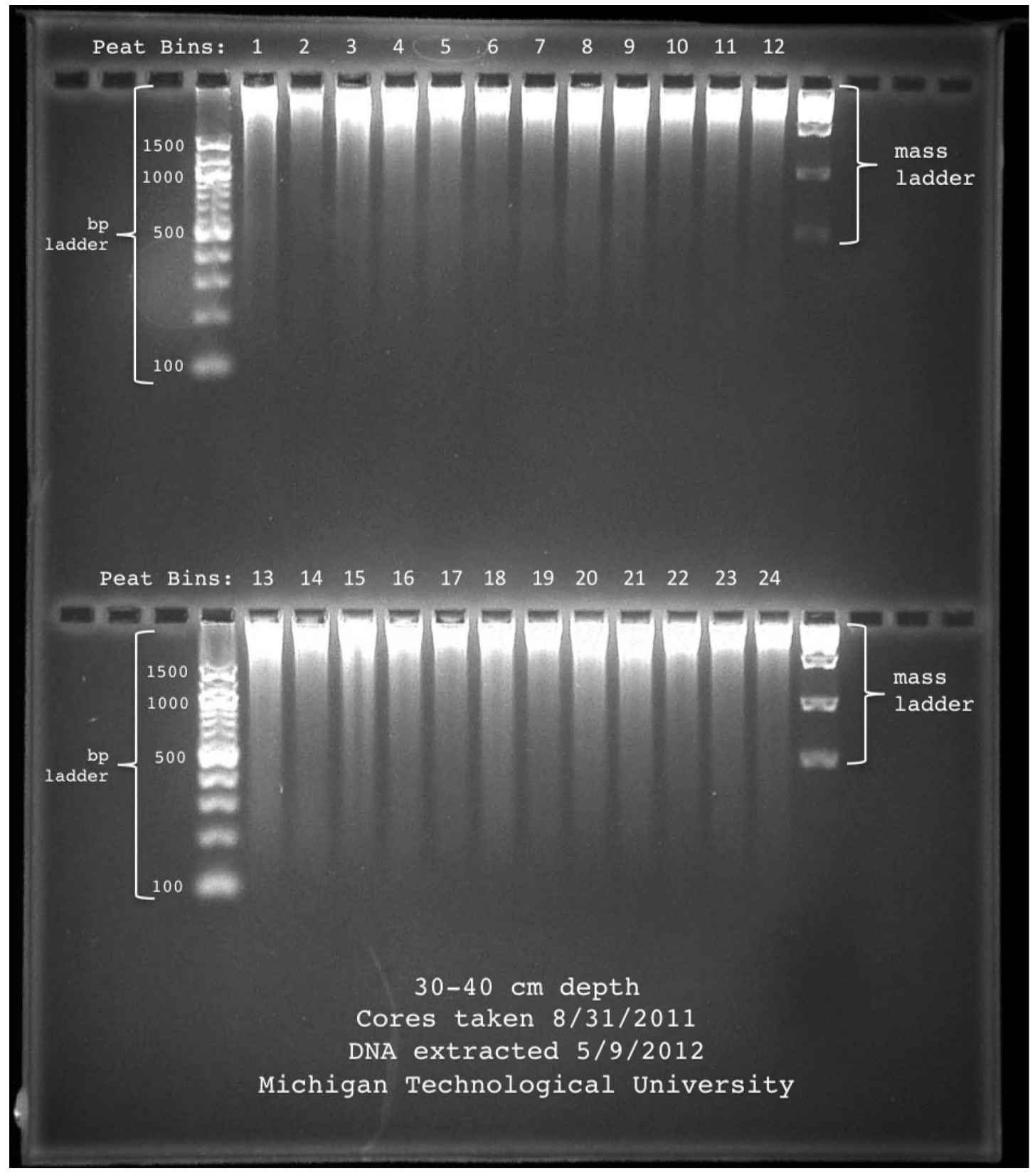

Figure S2 Electrophoresis DNA quantity visualization on 2:1\% agarose gel for DNA extractions at the $30-40 \mathrm{~cm}$ depth. 

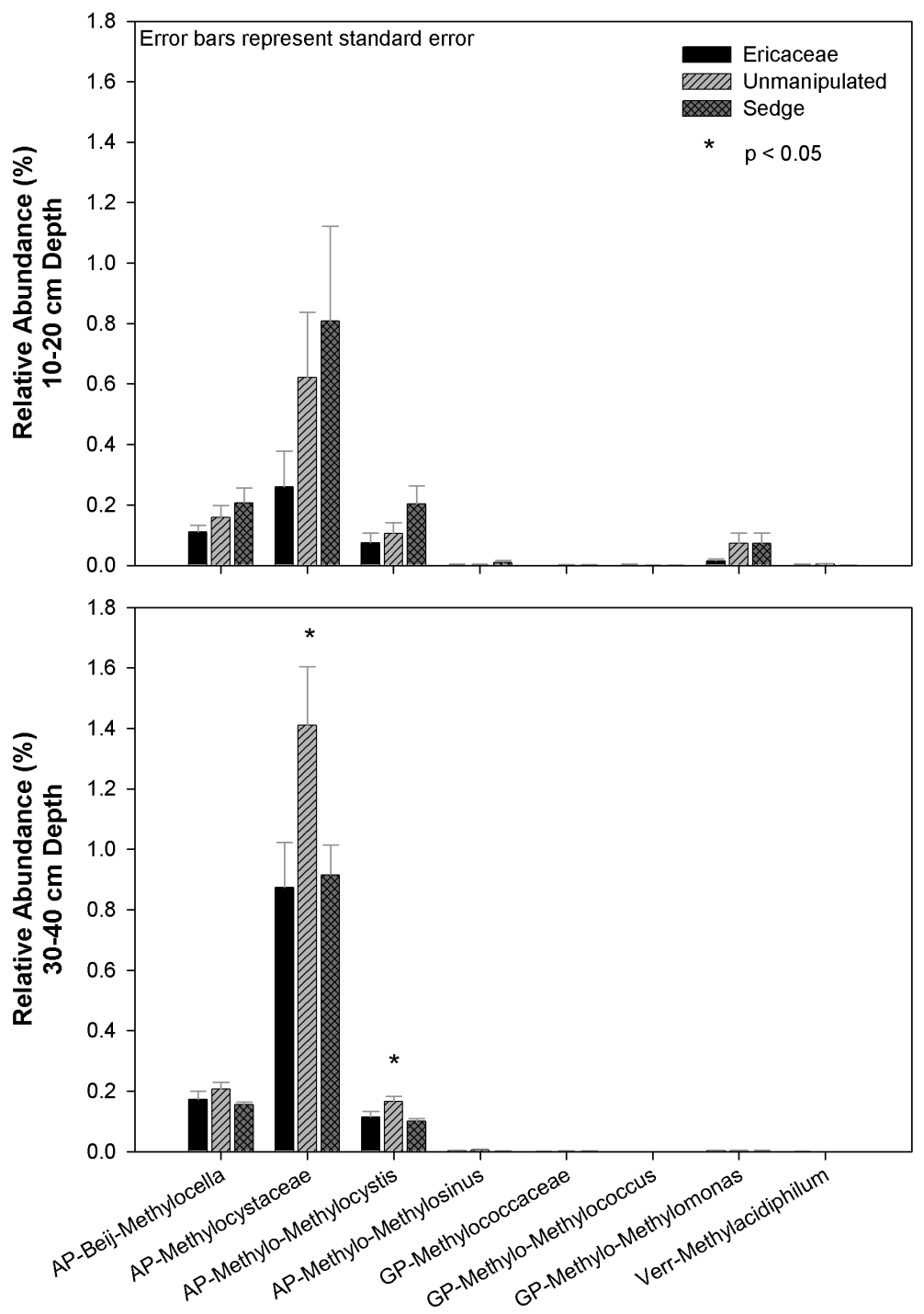

Figure S3 Relative abundance of all known methanotrophic bacteria within plant functional group treatments between sampling depths as found in this study. $\mathrm{AP}=\mathrm{Alphaproteobacteria,} \mathrm{GP}=\mathrm{Gammaproteobacteria,}$ Verr=Verrucomicrobia. 

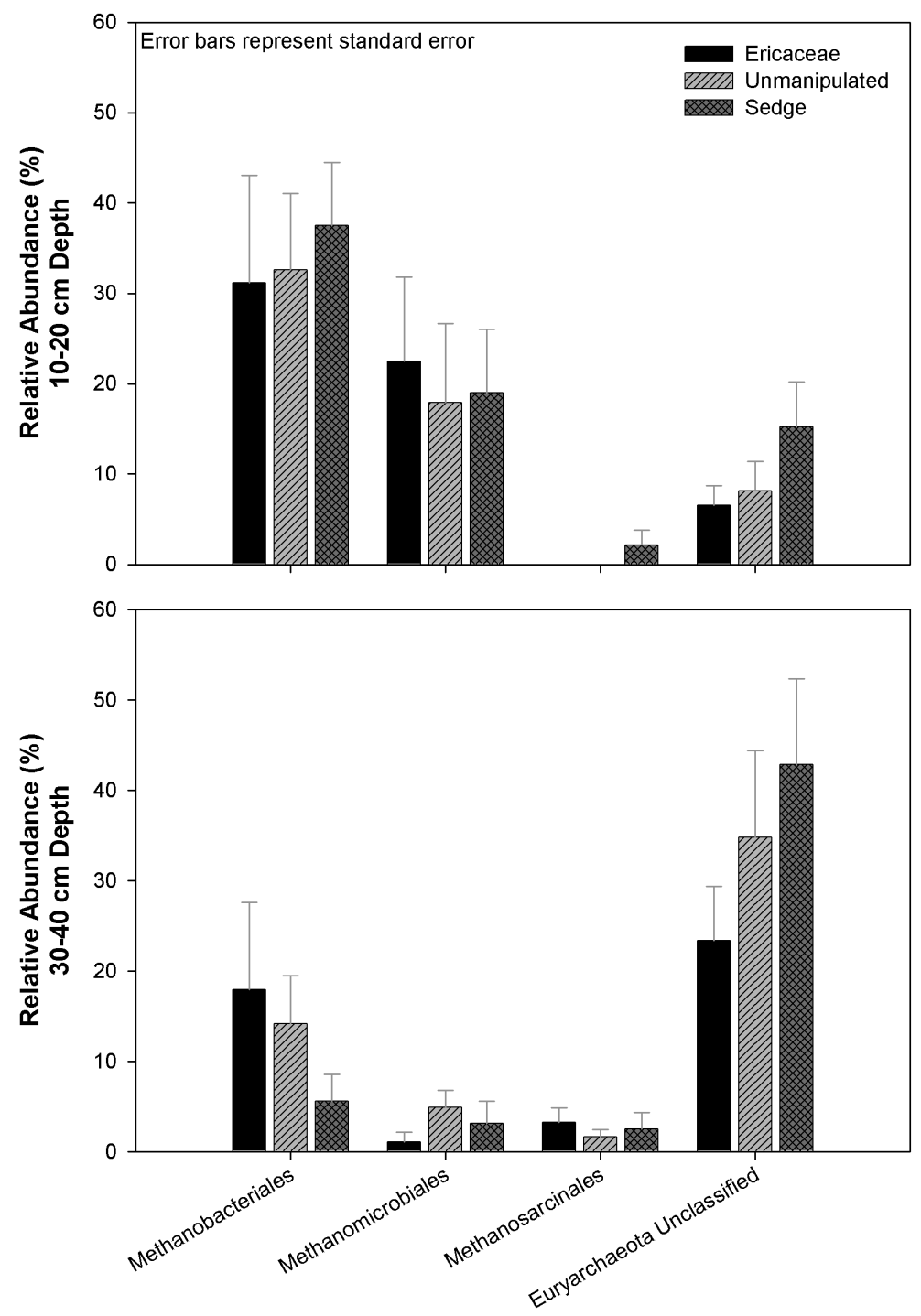

Figure S4 Mean relative abundance of all known methanogenic archaea plus unclassified Euryarchaeota within plant functional group treatments between sampling depths as found in this study. 